\title{
TRANSFORMACIONES EN LAS INVESTIGACIONES ANTROPOLÓGICAS sobre naturaleza, ecología
y medio ambiente*
}

\author{
Astrid UlloA
}

INVESTIGADORA DEL INSTITUTO COLOMBIANO DE ANTROPOLOGÍA E Historia aulloa@mincultura.gov.co

\section{Resumen}

[ N LAS INVESTIGACIONES ANTROPOLÓGICAS HA HABIDO UN LARGO PROCESO DE TRANS[ formación e interacción de la noción moderna de la naturaleza con nociones híbridas de cuasi-objetos y cuasi-humanos, así como la transformación de las concepciones de la naturaleza de una entidad apolítica a construcciones sociales con implicaciones políticas. Para analizar estos procesos, este texto presenta una revisión teórica de los cambios que se han dado en las categorías e investigaciones antropológicas sobre naturaleza, ecología y medio ambiente. Se destacan dos tendencias: la primera, ligada al replanteamiento de la dicotomía naturaleza/cultura a la luz de los conocimientos locales. La segunda, relacionada con los aportes de la ecología política, enfatizando el papel de los diferentes actores dentro de los discursos ambientales. Finalmente, se contextualizan las perspectivas de investigación sobre naturaleza, ecología y medio ambiente en América latina y en Colombia.

\section{ABSTRACT}

W ITHIN ANTHROPOLOGICAL RESEARCH, THERE HAS BEEN A LONG PROCESS OF INTERACTION and transformation between the modern and dichotomized notion of nature and hybrid notions of quasi-objects and quasi-humans. This has transformed the conception of nature as an apolitical entity to that of a cultural construct with political implications. This is a theoretical review of the implied transformations within anthropological categories and research in relation to nature, ecology and environment. Two tendencies are noted. The first is related to rethinking the conception of a nature/culture duality in the light of local knowledge, and the second is related to the contributions of political ecology and the role of various social actors within the environmental discourses. Finally there is a presentation of the perspectives in anthropological research in relation to nature, ecology and environment in Colombia and Latin America.

Revista Colombiana de Antropologia

Volumen 37, enero-diciembre 200I, pp. I88-232 


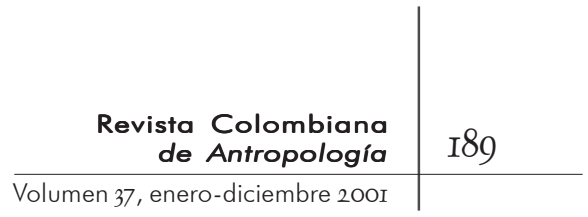

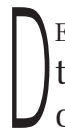
ENTRO DE LAS INVESTIGACIONES ANTROPOLÓGICAS, EN EL DEBATE teórico las conceptualizaciones sobre la naturaleza como construcciones sociales empiezan a ser consideradas importantes y productivas. Esto ha implicado un largo proceso de transformación e interacción de la noción occidental-moderna sobre la naturaleza -la cual se opone a la sociedad-con nociones híbridas de cuasi-objetos y cuasi-humanos, así como la transformación de las concepciones de la naturaleza como una entidad apolítica hasta nociones de ésta * Este texto fue realizado como parte de la investigación "El nativo ecológico. Movimientos indígenas y modernidades alternativas en Colom-

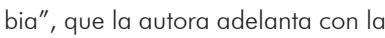

cofinanciación de Colciencias. caciones políticas.

La interacción de diferentes concepciones sobre la naturaleza supone el reconocimiento de ésta como una construcción social que se transforma de acuerdo con condiciones y situaciones históricas y sociales particulares. La naturaleza se siente, conceptualiza y construye de manera diferente de acuerdo con procesos sociales basados en contextos materiales, instituciones sociales, nociones morales, prácticas culturales e ideologías particulares. Estas prácticas, concepciones y nociones establecen maneras de percibir, representar, interpretar, usar e interrelacionarse con las entidades no humanas. Género, clase, raza, edad, prestigio social y etnicidad son conceptos que también atraviesan las construcciones sobre la naturaleza dando como resultado diversos significados sobre la misma.

De esta manera, nociones particulares sobre la naturaleza, la ecología o el medio ambiente están en constante interrelación con otras; esta interrelación, sin embargo, incluye procesos de negociaciones y conflictos sobre su significado, lo cual es político. Así mismo, implica que los cambios ambientales no son neutros y que el acceso, los beneficios y costos de los recursos naturales sean mediados por relaciones desiguales de poder. También requiere pasar de una noción prístina de la naturaleza a un medio ambiente politizado.

Para dar cuenta de este proceso, este texto presenta una revisión teórica sobre las nociones de naturaleza e historia y de las transformaciones ocurridas en la categorización antropológica sobre la naturaleza, la ecología y el medio ambiente, hasta llegar a las tendencias teóricas más recientes, destacando dos de ellas en los estudios antropológicos: una ligada al replanteamiento de la dicotomía naturaleza/cultura, y la otra relacionada con 
los aportes de la ecología política, enfatizando el papel de los diferentes actores en los discursos ambientales. Finalmente, se contextualizan las perspectivas de investigación antropológica sobre naturaleza, ecología y medio ambiente en América latina $\mathrm{y}$ en Colombia.

\section{Nociones SOBRE LA NATURAlezA}

$\bigcap$

IVERSAS NOCIONES SOBRE LA NATURALEZA HAN COEXISTIDO EN UN MISmo escenario social y de acuerdo con situaciones históricas particulares. Así, por ejemplo, las inscritas en visiones monista y dualista han estado presentes en diversos tiempos y espacios. Sin embargo, ideas específicas de naturaleza han sido hegemónicas en momentos históricos particulares. De hecho, la concepción moderna de naturaleza ha alimentado las concepciones científicas y viceversa y, por supuesto, las investigaciones antropológicas.

Dos conceptos, que de una manera general pueden denominarse monista y dualista, han alimentado las discusiones sobre naturaleza en Occidente. Concepciones monistas sobre la naturaleza sustentaron las ideas renacentistas, que consideraban esta y la humanidad como parte de una única esencia divina que estaba en constante movimiento. El hombre era uno con el cosmos y su conocimiento de la astronomía, las matemáticas, la música y la metafísica eran parte del proceso de entendimiento de la cadena divina de la vida.

El universo estaba conformado por diversas esferas -planetas, estrellas y seres divinos: ángeles, arcángeles y serafines, entre otros- y en medio de él estaba la Tierra en la cual los humanos recibían la influencia de las esferas superiores. Dios creó a los seres humanos, de esta manera ellos podían entender por medio de su intelecto el deseo divino. Sin embargo, el intelecto humano tenía la capacidad del libre albedrío y podía ser seducido por las tentaciones, por lo que podía aparecer la corrupción. Por tanto, los humanistas tenían que restaurar la vida humana.

Esta concepción de la humanidad y del universo se basó en la idea de un pasado considerado mejor que el presente, un pasado dorado de pureza (Latour, I993). De acuerdo con Bruno Latour, hubo una proliferación de culturas-naturales, que establecían 


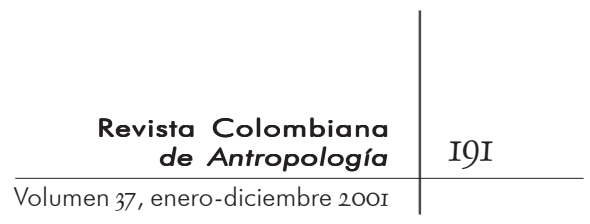

relaciones híbridas y dinámicas sociales particulares en las cuales no había separación entre lo natural y lo social.

\begin{abstract}
Antes de la revolución científica, la visión del mundo era de encantamiento; rocas, árboles, ríos y nubes se contemplaban como algo maravilloso y con vida... El destino de cada ser se concebía como ligado al del cosmos y es esta relación la que daba "un sentido" a su vida (Rogel y Aguado, 2000: I66).
\end{abstract}

La modernidad, en contraposición, surge de la separación entre humanos y no humanos y entre el arriba -la metafísica trascendental- y abajo -los humanos, los hechos científicos y los ciudadanos-. Así mismo, alude a un esquema universal y unificado para explicar el mundo y a un orden y estructura cerrada para entender los hechos sociales y naturales. De acuerdo con Latour (I993), modernidad, moderno y modernización indican "un nuevo régimen, una aceleración, una ruptura, una revolución en el tiempo" (Latour, I993: IO). Este régimen implica un contraste con un pasado arcaico y estable. De esta manera, lo moderno "designa dos campos separados de prácticas que han de permanecer distintas para permanecer efectivas" (IO). De acuerdo con Latour, estas dos prácticas son de traslación y de purificación. Las de traslación producen "mixturas entre nuevos tipos de seres, híbridos naturales y culturales" (Io). Sin em-

I. Las citas de los textos en inglés son traducciones realizadas por la autora.

bargo, las prácticas de purificación que crean "dos zonas ontológicas distintas: la de los seres humanos en una mano, y la de los no humanos en la otra"(Io) son las que sustentan el pensamiento moderno. De esta manera, la modernidad como una formación social específica consolidó no sólo la idea de estado-nación y de los individuos como ciudadanos, sino también prácticas encarnadas que establecen una relación específica entre humanos y entre humanos/no humanos.

De acuerdo con Rogel y Aguado (2000) "en la época moderna se tiene una visión de desencantamiento continuo, donde (sic) los puntos de referencia de toda explicación científica (moderna) recaen en la materia y el movimiento" (I66). De esta manera, la separación entre humanos y no humanos se expresa en la idea de controlar y dominar lo natural mediante procesos técnicos y se refleja en la concepción sobre la naturaleza que expresa el dualismo naturaleza/cultura. 
Este proceso comenzó en el periodo renacentista y se consolidó en la Europa posrenacentista, pues uno de los aspectos más importantes fue el uso de las leyes de la perspectiva, que permitió a los humanos cuantificar y controlar la naturaleza en espacios tridimensionales. De acuerdo con Pálsson, en el pensamiento occidental moderno, conocer la naturaleza ha sido posible por medio de dos procesos diferentes: explotación y protección, a los cuales esta autora denominó explotación orientalista y protección paternalista. La explotación implica la apertura de fronteras y la expansión del control humano mediante la domesticación de lo natural -colonización-. La protección supone la responsabilidad humana por el cuidado de otras especies -los humanos actuando en nombre de la naturaleza- (Pálsson I996). En ambos procesos, los humanos -hombres- son los dueños de la naturaleza, que puede ser conquistada o protegida dado que se considera algo inferior y asociado a la animalidad, lo que implica la creación de fronteras conceptuales y prácticas específicas para relacionarse con ella. Estos procesos también se relacionan con las nociones occidentales de género. Escobar (I999) considera la naturaleza dualista como esencial del capitalismo la cual surgió “en la Europa pos-renacentista y cristalizó con el capitalismo y el advenimiento de un orden epistémico moderno hacia finales del siglo XVIII" (286).

La noción moderna sobre la naturaleza puede variar de acuerdo con situaciones históricas, espaciales y sociales particulares, desde la explotación de bosques silvestres hasta la protección de los parques urbanos o las especies en extinción. Así, en el pensamiento occidental la naturaleza ha tenido diferentes significados en contextos urbanos y rurales y en dominios religiosos y técnicos, de forma tal que puede llegar a tener una variedad de valores, pero siempre bajo la concepción dicotómica de naturaleza/cultura. Todas estas imágenes sobre la naturaleza tienen en común la idea de una entidad externa que escapa al orden cultural y racional al igual que al de los cálculos instrumentales y de la eficiencia técnica.

La noción de la naturaleza como algo externo implica que ésta es un medio para satisfacer necesidades individuales y sociales. Así mismo, que puede ser poseída, lo que implica la noción de propiedad. La racionalidad de la modernidad permite también que lo natural pueda ser abstraído de su espacio como una mercancía o un producto (Ellen, I996a, I996b; Ingold, I996a, 


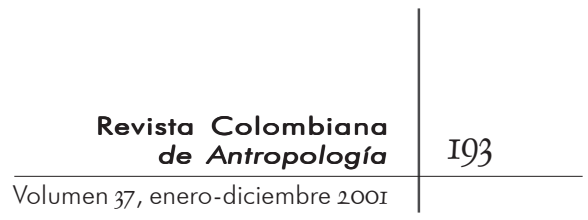

I996b; Blatter et al., 200Ia). La naturaleza puede ser "racionalizada y controlada por medio de leyes, instituciones y estructuras organizativas" (Blatter et al., 200Ib: 3I). Ésta es la victoria de la razón humana sobre la naturaleza, que puede ser poseída, movida, comprada y vendida de acuerdo con los dictámenes de los intereses individuales y del poder económico “ (Blatter et al., 200Ia).

Por estas razones, las formas modernas de gobernabilidad de la naturaleza implican procesos de control, transformación, contabilidad y dominación de lo natural -pudiendo ser estas desde los bosques-jardines a los instintos biológicos o los virus- para transformarlo en una categoría de conocimiento -una categoría científica-. Éste fue el inicio de la era en la que el orden de lo natural puede ser conocido mediante la mirada especializada. La separación de la naturaleza y la cultura comenzó a ser reificada en las ciencias naturales y sociales en el siglo diecinueve. Esta concepción de la naturaleza se enmarcaba perfectamente en las perspectivas evolucionistas. En la tradición moderna, la naturaleza se ha convertido en un objeto de conocimiento que no incluye relaciones humanas en ella. Sin embargo, la separación de los humanos y no humanos puede llegar a implicar que lo natural es inagotable, en el sentido de que, bajo un control y dominio cuidadoso por medio de procesos técnicos, ésta puede ser producida y reproducida en el tiempo -ejemplo: de la clonación y la reproducción in vitro-.

Ellen (I996a) resalta cómo "el concepto de naturaleza como una categoría científica, al igual que para el discurso político, es básicamente de la Ilustración [Williams, i976: I8], aunque ésta empezó a encontrar su expresión moderna hacia finales del siglo XVIII” (I996a: I3). Esta visión científica de la naturaleza fue diseminada como una categoría hegemónica no solamente dentro del ámbito de la ciencia moderna y seculares sino también alrededor del mundo.

Avances en las ciencias naturales y sociales $^{2}$ han llevado a replantear las fronteras modernas entre naturaleza y cultura, $\mathrm{y}$ a proponer una nueva noción de naturaleza como múltiple y socialmente construida (Ellen I996a, I996b; Ellen y Fukui, I996; Dwyer, 1996; Strathern I992; Descola y Pálsson, I996; Haraway I991; Escobar, I996, I999;

2. Los principales desarrollos conceptuales se dieron en la ecología, genética, biología, etnobiología, teoría social -posestructuralismo y posmodernismo-, epistemología, sociología de la ciencia, ecología social y humana, geografía, etnografía, comunicación y tecnología, entre otras. 
Blatter et al., 200Ia, 200Ib; Little, 1999). El pensamiento posmoderno replantea las nociones modernas al hacer énfasis en la diferencia, la pluralidad, la fragmentación y la complejidad. Lo posmoderno implica pensar en organismos, reintegración con la naturaleza, materia activa, incertidumbre, caos, complejidad, probabilidad, interpretación, relatividad del tiempo y el espacio, entre otros, lo que afecta a las ciencias naturales y a la teoría social. Las nuevas perspectivas científicas permiten cuestionar las verdades modernas, universales y estables e introducir un diálogo entre las diferentes ciencias, lo que ha llevado a la crítica de las categorías universales tales como progreso, desarrollo, género y naturaleza. De esta manera, concepciones monistas, dualistas e híbridas coexisten; sin embargo, la actual visión de interrelación con la naturaleza ya no se centra en el concepto de articulación con la divinidad externa.

Entre todas estas reconsideraciones sobre las concepciones modernas de naturaleza los antropólogos han sido importantes al traer a la discusión en las ciencias modernas y el pensamiento moderno nuevas concepciones sobre naturaleza, en las que la dicotomía entre ésta y cultura es inaplicable. Para discutir las transformaciones históricas de las corrientes teóricas relacionadas con lo natural me centraré en la perspectiva antropológica.

VISIONES DESDE LA HISTORIA

DE LA ANTROPOLOGÍA SOBRE

LA RELACIÓN NATURALEZA/CULTURA

F l DESARROllo de la ANTROPOlOGía COMO CIENCIA IMPLICÓ la DEFIy unos objetos de estudio, que surgieron en medio de las discusiones de las ciencias naturales a finales del siglo diecinueve y comienzos del siglo veinte. Esta situación ayudó a situar a la antropología como una ciencia importante en la definición de la oposición naturaleza/cultura. La fragmentación del saber científico y la especialización llevaron a que los antropólogos empezaran a centrarse en la cultura y a señalar su importancia en el proceso de humanización. Estas discusiones ayudaron a establecer a la cultura como un campo separado que formaba parte de las ciencias sociales y humanas. La oposición naturaleza/cultura 


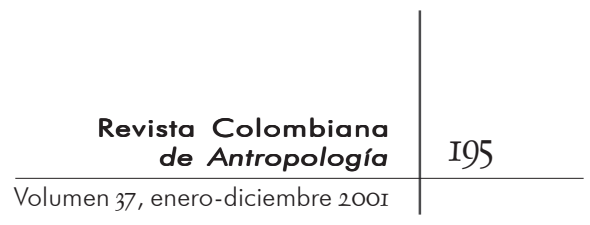

fue importante en la definición y legitimación de los límites disciplinarios; sin embargo, también permitió la reproducción y naturalización de los dualismos modernos tales como cuerpo/ mente, mujer/hombre y público/privado, entre otros (Ellen, I996a, Kuclin, 1996).

Las categorías duales fueron impuestas para analizar e interpretar diferentes culturas y sus concepciones ecológicas. Por ejemplo, en el análisis sobre el hombre económico frente al cazador-recolector, el primero tenía la capacidad de trabajar mientras que el segundo era determinado por el medio ambiente. Aun cuando los antropólogos localizaban las prácticas locales -indígenas en América, aborígenes en Australia o África- como una interrelación total entre naturaleza y cultura, estaban reafirmando la concepción dual de naturaleza/cultura -las sociedades indígenas eran entidades naturales externas en las que todo era interrelacionado sin control, mientras que las sociedades occidentales eran culturas racionales gobernadas por dominios separados-.

A la luz de la dicotomía moderna de naturaleza/cultura las relaciones entre la gente y su entorno han sido centrales para la investigación antropológica. De acuerdo con Milton (I996) ha habido tres fases distintas: una, centrada en los factores ambientales y su incidencia sobre los fenómenos sociales, es decir, los humanos se adaptan al medio ambiente y, por tanto, son condicionados por él -determinismo ambiental-; otra centrada en los efectos de los procesos culturales en el entorno, es decir, los humanos se adaptan al medio ambiente para suplir sus necesidades y, por tanto, condicionan su medio ambiente -determinismo cultural-; y finalmente una perspectiva ecosistémica en la que se analizan las interrelaciones de los humanos con su ambiente y la manera en que se condicionan mutuamente. Sin embargo, los dos determinismos están inscritos en uno de los dos polos de la dicotomía naturaleza/cultura.

\section{Las oscilaciones entre la naturaleza y la cultura}

T A OPOSICIÓN NATURALEZA/CULTURA DIO HERRAMIENTAS TEÓRICAS Y ـ alimentó la producción de la antropología ecológica hasta 
la década de 1970. Los antropólogos interesados en los humanos y sus relaciones con el medio ambiente analizaron las técnicas de subsistencia, las prácticas ecológicas, las concepciones relacionadas con la naturaleza y los comportamientos humanos. Esta perspectiva consideraba al dualismo naturaleza/cultura bajo una concepción esencialista que se reflejaba en las tendencias iniciales de la antropología ecológica.

Leslie White (1949), por ejemplo, consideraba que el medio ambiente era constante y que la capacidad humana para capturar energía de él era la posibilidad para la evolución cultural en una perspectiva evolucionista unilineal. Por otro lado, la ecología humana, bajo una perspectiva funcionalista, consideraba la naturaleza como parte constituyente del comportamiento social. De esta manera, teóricos de esta escuela usaban los modelos de las ciencias naturales para analizar a los actores sociales. Las instituciones sociales se analizaban en términos de competencia y áreas y zonas geográficas (Steward, I977).

Los primeros trabajos en ecología cultural se centraron en procesos por los cuales una sociedad se adaptaba a su ambiente (Steward, 1977). De esta manera, se analizaba la interacción entre la sociedad y sus instituciones y entre ésta y el medio ambiente. Julian Steward se centraba en las maneras como la gente "usaba la tecnología para explotar y transformar el ambiente por medio de la producción" (Painter, I995: 3). Se partía de la idea de que ambientes similares afectaban diferentes estructuras sociales en forma similar, lo que permitía explicar divergencias y convergencias de las estructuras sociales, por ejemplo en sociedades de cazadores o en estados. La ecología cultural buscaba dar cuenta del "comportamiento en términos de características preestablecidas y heredadas de individuos particulares" (Ingold, I996b: 26).

Las corrientes neoevolucionistas y neofuncionalistas surgieron en la antropología ecológica como respuesta a los trabajos de White y Steward. El neoevolucionismo articulaba las propuestas de los dos teóricos para plantear una evolución multilineal basada en la idea de una evolución general y específica que reflejaba el método de Steward sobre la ecología cultural y la visión de White de una evolución unilineal. Bajo este enfoque se destacan los trabajos de Elman Service. El neofuncionalismo veía "la organización social y la cultura de poblaciones específicas como adaptaciones funcionales que permiten a la población explotar su medio ambiente exitosamente sin exceder su capacidad de carga" 


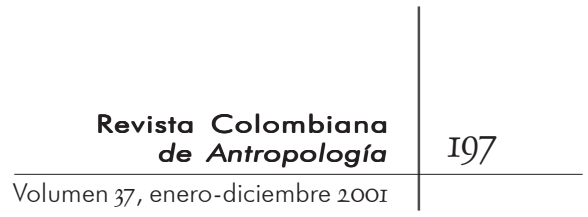

(Orlove, I980: 240). Bajo esta perspectiva, aspectos de la organización social y de la cultura eran explicados en términos de adaptación, pero planteando una interacción entre el medio ambiente y la población en cuestión. Este enfoque se asocia con los trabajos iniciales de Marvin Harris (1966), Andrew Vayda (I976) y Roy Rappaport (1967, I97I). Aunque estas dos tendencias pretendían tener diferencias conceptuales, ambas perspectivas consideraban a las poblaciones humanas y su interacción con el medio ambiente de manera similar a las interacciones de otras especies; por tanto, se concentraban en los ciclos de energía y nutrición. La visión de ecosistema, aunque fue importante en sus análisis, se centró con demasiado énfasis en los procesos de supervivencia y reproducción.

En los análisis antropológicos culturalistas la naturaleza fue considerada como una entidad externa y prístina, el otro, sobre la cual el ser racional podía proyectar sus particularidades (Ingold, I996a, I996b; Ellen, I996a, I996b; Kuclin, I996; Little, I999). Los etnocologistas empezaron a analizar el conocimiento indígena de acuerdo con las categorías científicas occidentales-modernas acerca de la relación naturaleza/cultura, como si éstas fueran universales, sin considerar las conceptualizaciones de culturas no occidentales. De manera similar, en la perspectiva estructuralista, la oposición naturaleza/cultura fue utilizada para el análisis de mitos, rituales, clasificaciones y prácticas, pero dando mayor importancia a las concepciones culturales. La búsqueda hecha por el estructuralismo de oposiciones universales y el reconocimiento de un plan básico de la naturaleza impedía reconocer las entidades y los fenómenos que no se ajustaban a la noción occidental de naturaleza.

Estas perspectivas -ambiental o cultural-, en general, introdujeron las primeras discusiones dentro de la investigación antropológica sobre la naturaleza, la ecología y el medio ambiente. Sin embargo, en estas corrientes teóricas -ecología cultural, antropología ecológica, materialismo histórico, etnocología, en sus inicios y estructuralismo, entre otros- se consideraba que las comunidades humanas eran autónomas, y la relación medio ambiente/sociedad fue mirada como un sistema local cerrado estable y armónico. La relación sociedad/medio ambiente se veía como dentro de un sistema autocontenido y en equilibrio. El comportamiento humano, las actividades sociales y los lineamientos culturales se concebían como "respuestas adaptativas a, o puras 


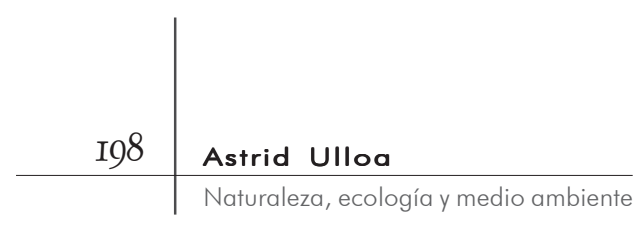

expresiones de, el medio ambiente básico o de determinantes genéticos” (Descola y Pálsson, I996); o modelos conceptuales o experiencias sociales que se inscribían en el entorno natural.

Estos estudios se centraban en describir las prácticas y las situaciones y no en analizar las interrelaciones de prácticas particulares con respecto a contextos regionales, nacionales e internacionales. En general, no se consideraban los procesos de control, acceso y políticas de manejo de los recursos naturales ni su interrelación con cambios históricos. De esta manera, la dimensión política de la interacción entre los humanos y el medio ambiente no se tenía en cuenta (Durham, I995a, I995b; Painter, I995). Así mismo, estos enfoques daban poca importancia a las concepciones acerca de la naturaleza y a las relaciones que tienen con ella las culturas no occidentales, lo cual hacía difícil entender las formas locales del conocimiento ecológico.

El paradigma dual naturaleza/cultura ha tenido diferentes implicaciones al analizar las relaciones de diversas sociedades con su entorno. Por ejemplo, los aspectos biológicos y evolutivos se usaron para analizar aspectos sociales en los que estos últimos se consideraban estructuras normativas que constreñían a los humanos a utilizar todas sus estrategias heredadas (Descola y Pálsson, 1996). Por el contrario, el énfasis en la racionalidad económica de los actores sociales fue utilizado para analizar las relaciones con el medio ambiente, presentando a la naturaleza como embebida de posibilidades racionales. Descola y Pálsson (I996) consideran que esta oposición -naturaleza/cultura- previene el tener un "adecuado entendimiento de las formas locales de conocimiento ecológico y de los procesos técnicos del saber-hacer (know-how), dado que estos tienden a ser objetivados de acuerdo con los estándares occidentales" (I996: 4).

\section{La interrelación entre los humanos y el medio ambiente}

I A RELACiÓN DUAL NATURALEZA/CULTURA COMENZÓ A SER CUESTIONA$ـ$ da por diferentes tradiciones teóricas en las ciencias sociales y en las naturales. Por ejemplo, nuevas perspectivas en las teorías biológicas asumen que los organismos pueden remodelar su propio desarrollo. Otros teóricos consideran que las relaciones 


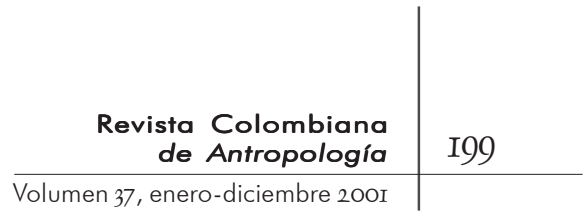

entre organismos y medio ambiente son recíprocas. De una manera similar, estudiosos de la etología de primates han encontrado que los chimpancés hacen herramientas, lo cual permite reconsiderar la relación humanos/cultura. En estudios etnográficos sobre entrenamiento y destrezas, las concepciones sobre los individuos frente al medio ambiente o los individuos frente a la sociedad han sido reconsideradas al introducir la idea de "la capacidad de acción" (agency) de los individuos en los procesos de aprendizaje, lo que introduce una visón dinámica en las acciones del individuo en relación con su medio ambiente (Descola y Pálsson, 1996). De una manera similar, desarrollos en ecología cultural (Hjort, I982; Vayda, I983; Burton y White, 1984) permitieron situar las interacciones particulares entre humanos y medio ambiente en relación con amplias estructuras políticas, económicas y sociales.

Diferentes antropólogos (Moran, I996; Ellen, I996; Posey, I984; Posey et al., 1982) comenzaron a profundizar en los sistemas de conocimiento indígena y a plantear cómo éstos están basados en concepciones complejas y diferentes sobre la naturaleza, retomando el concepto de ecosistema. Así mismo, el cambio de perspectivas dentro de la etnoecología permitió el acercamiento a concepciones sobre la naturaleza que no respondían a las categorías occidentales sino a nociones y conocimientos locales articulados con la tradición histórica, étnica, social y cultural de los mismos. Estos estudios en poblaciones locales empezaron a incluir análisis de subdisciplinas tales como la etnobiología, etnobotánica, etnoentomología y etnozoología, que incluían las categorías locales como factores importantes que debían ser analizados (Gragson y Blount, I999; Nazarea, 1999).

Estos replanteamientos se vieron reflejados a finales de la década de 1970 e inicios de la de 1980 en la denominada antropología ecológica procesual (Orlove, I980) que considera la relación organismo/medio ambiente como un proceso dinámico que replantea el dualismo naturaleza/cultura dado que permite un análisis relacional y perspectivista. De acuerdo con Milton (I996), en este enfoque se deja de lado la cultura para ver las relaciones entre humanos y entorno como interacciones que se constituyen mutuamente bajo un modelo ecosistémico. En el mismo son de vital importancia la dimensión diacrónica y los procesos de variabilidad y diversidad en el ámbito individual y grupal. De esta manera se introdujeron análisis centrados en las opciones 


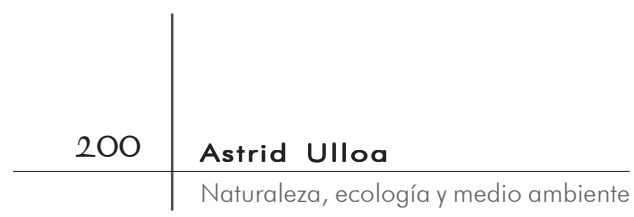

3. Miembros de organizaciones conservacionistas, radicales de izquierda, al igual que expertos, técnicos y miembros de la clase media conformaron los movimientos ambientalistas que surgieron al final de los años I960 y comienzos de la década de 1970. Las actividades que lideraron estos movimientos en contra de los proyectos de desarrollo tales como la construcción de carreteras o torres petroleras, centros urbanos de gran escala y la contaminación y polución de la tierra, el agua y el aire, ayudaron a replantear las concepciones sobre la naturaleza. Desde ese entonces han surgido diversos movimientos ambientales - desde los defensores de los parques naturales hasta las acciones mundiales de Greenpeace- que unidos a movimientos de mujeres y diversos grupos sociales se han resistido a la reforestación científica, los programas de desarrollo -hidroeléctricas, micro centrales, etcétera-y proyectos industriales de gran escala, exigiendo un enfoque diferente a los análisis tradicionales antropológicos. De manera similar, las organizaciones de base han luchado por el control de sus recursos en contra de imposiciones externas de programas de desarrollo y por mantener sus conocimientos y prácticas relacionadas con la naturaleza. Así mismo, los movimientos indígenas han encontrado una poderosa coalición con los movimientos ambientalistas con los que comparten acciones para proteger sus territorios y recursos naturales (Fisher, I995; García, I992; Klandermans y Tarrow, I988; Linkenbach, I992; Omvedt, I993; Princen, I994; Wapner, I994).

individuales de acuerdo con relaciones sociales, económicas y políticas, al igual que los procesos de conflicto y cooperación (Orlove, 1980; Little, 1999; Milton, I996).

Así mismo, el aumento de los cambios ambientales en el ámbito global permitió el desarrollo paralelo de una investigación antropológica sobre aspectos que relacionaban contextos particulares con problemáticas ambientales globales. Los problemas globales ambientales y los cuestionamientos teóricos sobre los procesos de adaptación permitieron un replanteamiento en los análisis sobre la relación ser humano/medio ambiente. Estos replanteamientos fueron alimentados por los movimientos ambientalistas y ecológicos ${ }^{3}$, los cuales han traído a la investigación sobre lo ambiental nuevas discusiones sobre derechos ambientales, territoriales y sobre el papel que tienen los discursos ambientales en las relaciones entre humanos y medio ambiente. De igual manera, el ambientalismo afectó las nociones sobre la naturaleza y las perspectivas antropológicas, al introducirse como una nueva categoría que al ser analizada hizo más compleja la unión entre lo natural y lo social (Milton, I996; Brosius, 1999).

\section{La deconstrucción de las categorías duales}

ESDE El FINAL DE LA DÉCADA DE I980 E INICIOS DE I99O LAS CRítICAS posmodernas de las concepciones occidentales también han permitido la deconstrucción y reconfiguración de las oposiciones modernas de naturaleza/cultura, cuerpo/mente, emoción/ razón, al igual que la de mujer/hombre. Estas críticas han 


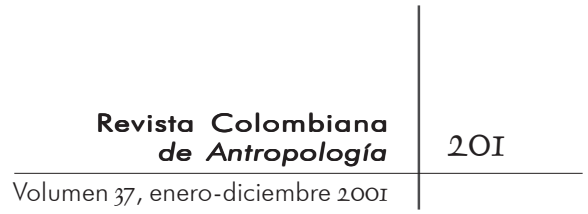

contribuido a reconsiderar epistemologías y metafísicas modernas y a examinar las nociones y representaciones de cultura y naturaleza como socialmente construidas. Por ejemplo, la revaloración de categorías duales como la de mujer/hombre desde el punto de vista feminista ha replanteado las nociones occidentales de género. De hecho, la antropología feminista ha reconsiderado esta dualidad al plantear que cada cultura y cada noción de género son resultado de procesos de construcción social antes que de procesos naturales. Así mismo, ha resaltado que para entender las situaciones sociales de las mujeres es necesario relacionar género con nacionalidad, clase, raza, edad, prestigio, etnicidad y preferencias sexuales. De esta manera, propuso una alternativa a los marcos conceptuales tradicionales para entender no solamente las construcciones occidentales sino también culturas no occidentales a la luz de sus propias categorías. Replanteamientos que aportaron en la redefinición de la categoría naturaleza/cultura (Haraway, I988; Di Leonardo, I99I; Behar y Gordon, I995).

\section{LA NATURALEZA Y EL MEDIO AMBIENTE EN LAS ACTUALES TENDENCIAS TEÓRICAS ANTROPOLÓGICAS} AS NUEVAS INVESTIGACIONES QUE ANALIZAN A LA NATURALEZA COMO
un ente con capacidad de acción y con un dinamismo propio
replantean la visión de una naturaleza pasiva o prístina. La naturaleza y la cultura como construcciones sociales implican que los humanos no son determinados por el medio ambiente $\mathrm{y}$, a su vez, que la naturaleza no es determinada por los intereses individuales, lo que permite un nuevo entendimiento de la relación naturaleza/cultura como interdependiente e interactiva, en la cual ambas se afectan recíprocamente (Descola, I996; Blatter et al., 200Ia). Así mismo, los análisis sobre grupos sociales en contextos particulares evidencian cómo diversas nociones sobre la naturaleza responden a procesos históricos específicos.

De acuerdo con Little (I999) las transformaciones que se han dado en la antropología ecológica pueden sintetizarse en: I) Cambios en la concepción dual de naturaleza/cultura; 2) Introducción de análisis que articulan lo local, regional y global; 3) Nuevas 
concepciones de la historia; y 4) Replanteamientos sobre la espacialidad -territorio, lugar y paisaje-. Lo que permitió pasar de una antropología centrada en la oposición naturaleza/cultura a una perspectiva más amplia en la que conceptos como ecosistema y medio ambiente permiten unos niveles de análisis que consideran las relaciones entre los humanos y su medio ambiente en un sentido amplio que articula lo local, regional y global.

De esta manera, en este mundo posmoderno coexisten diferentes nociones sobre la naturaleza. Escobar (I999) identifica tres regímenes de naturaleza -capitalista, orgánica y tecno-naturaleza- como resultado de las situaciones históricas particulares de diferentes culturas. Cronon (I995) al analizar las preocupaciones ambientales contemporáneas identifica diversas nociones de naturaleza, que coexisten aún en un mismo escenario social. Así, la naturaleza puede ser entendida como un imperativo moral, el Edén, un artificio, una realidad virtual, una mercancía o como el diabólico extraño.

Estos diferentes significados implican procesos de negociación entre las diversas nociones de naturaleza; algunas se han vuelto hegemónicas mientras que otras son debatidas, repensadas o transformadas. Más aún, las luchas entre estas nociones de naturaleza tienen implicaciones políticas para actores sociales específicos. De esta manera, las nociones sobre la naturaleza, la ecología y el medio ambiente son terrenos de luchas los cuales están traspasados por relaciones de poder y dentro de un proceso permanente de negociación y resignificación (Moore, I993, 1996, 1997; Escobar, I998; Peet y Watts, 1996). En estas perspectivas se articulan análisis posestructuralistas sobre la naturaleza -que trascienden las concepciones duales y esencialistas- y concepciones sobre los actores sociales como actores políticos con capacidad de acción los cuales están en negociaciones constantes entre los contextos locales, nacionales y globales. En estos análisis se plantea que hay diferentes niveles y articulaciones internas. Por tanto, se ha pasado de un análisis ecosistémico -un grupo de gente con su ecosistema- a análisis globales que se centran en los humanos y su interrelación en el planeta (Little, I999).

Todos los desarrollos teóricos descritos han permitido que en la antropología las concepciones sobre la naturaleza se hayan transformado de una visión en la cual la naturaleza era una entidad exterior hasta convertirse en una construcción social que 


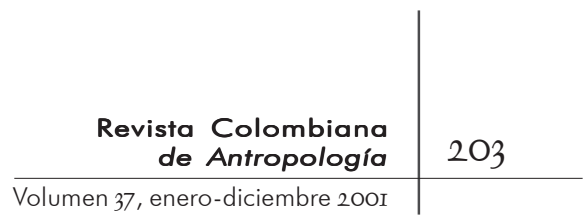

tiene implicaciones políticas. Entre las tendencias actuales en investigación antropológica hay varias perspectivas: la antropología ecológica analiza las interrelaciones entre humanos y su medio ambiente por medio de metodologías ecológicas, mientras que la antropología del ambientalismo (anthropology of environmentalism) se centra en análisis etnográficos para estudiar el ambientalismo como un tipo de acción humana. De otro lado, la ecología humana se centra en una perspectiva política y en análisis ecosistémicos. Los análisis sobre ambientes virtuales y las nuevas relaciones con los ambientes biofísicos que analizan, por ejemplo, el espacio virtual (cyberspace) y la biotecnología.

Finalmente, entre los actuales estudios sobre las interrelaciones sociedad y naturaleza destaco dos tendencias que tienen un desarrollo y propuestas interesantes, que han sido el resultado y el efecto de estas discusiones. La primera tendencia está ligada al replanteamiento de las categorías duales -naturaleza/cultura- a la luz de los conocimientos locales. En ésta pueden ubicarse, por ejemplo, los estudios sobre prácticas locales basadas en las categorías conceptuales y en los sistemas de conocimiento indígenas; y los estudios sobre mundos híbridos, tecnológica y socialmente. La segunda tendencia se centra de manera general en las interrelaciones de las prácticas locales con contextos amplios en el ámbito socioeconómico y político. Aquí podrían ubicarse la antropología del medio ambiente y la ecología política antropológica. Sin embargo, ambas tendencias tienen que ser combinadas para poder dar cuenta de las nociones y prácticas ambientales locales en un mundo global. A continuación describiré los puntos más importantes de estas dos tendencias.

\section{La naturaleza monista a la luz de los conocimientos locales}

$\mathrm{D}$ ESCOla y PÁlsSon (I996) CONSIDERAN QUe los trabajos ETNOgráficos han sido esenciales en la transformación de una perspectiva dualista a una monista. De hecho, varios investigadores (Descola, 1994; Ulloa, I996; Århem, 1996; Viveiros de Castro, I998) describen cómo, para algunas culturas indígenas, los animales y las plantas tienen comportamientos humanos y están regulados por reglas sociales. Mientras que, de manera recíproca, 
los humanos pueden transformarse en animales. Las relaciones entre humanos y no humanos están en constante proceso de transformación y reciprocidad. A la luz de estos análisis, la dicotomía naturaleza/cultura se vuelve visiblemente deficiente.

Las discusiones actuales en la antropología acerca de la relación naturaleza/cultura han retomado elementos de la perspectiva de Latour (I993) acerca de la modernidad y de los mundos híbridos. Latour plantea cómo aun en la idea occidental de naturaleza/cultura la oposición no ha sido posible porque cuando la modernidad divide y excluye mundos opuestos -naturaleza/ cultura-, al mismo tiempo permite la proliferación de lo híbrido -cuasi-objetos y cuasi-humanos-. Latour también expone que la consideración de dos prácticas simultáneas -la purificación moderna de dos ámbitos separados entre la naturaleza y la cultura, y la traslación que produce mixturas entre la naturaleza y la cultura-implica el final de ser "completamente moderno". En este sentido, tomar conciencia de estas dos prácticas cambia concepciones sobre el pasado y el futuro y, por extensión, cambia concepciones lineales del progreso. De la misma manera, la separación entre naturaleza y cultura deja de ser útil dado que al considerar estas dos prácticas la relación naturaleza/cultura produce, simultáneamente, humanos, no humanos y divinidades. Finalmente, Bruno Latour considera que la ciencia moderna siempre ha producido híbridos que claman una visión diferente y mixta.

De manera similar, varios teóricos de las ciencias sociales y naturales describen cómo la reconfiguración de los límites entre naturaleza/cultura está siendo moldeada por nuevas tecnologías en la reproducción humana (Strathern, I992), la creación de $c y$ borgs (Haraway, I99I), las realidades virtuales (Stone, I996) y la manipulación genética, las cuales confrontan concepciones sobre categorías tales como naturaleza/cultura, cuerpo/mente, mujer/hombre y humano/máquina, al igual que categorías temporales y espaciales. De hecho, por ejemplo, los cyborgs y las máquinas actuales forman parte de ambos mundos: el natural y el cultural. Como plantea Haraway "un mundo cyborg puede llegar a ser acerca de realidades sociales y corporalmente vividas en las cuales la gente no esté temerosa de tener relaciones de parentesco con animales y máquinas, ni de identidades constantemente parciales y puntos de vista contradictorios" (I99I: I54).

Para analizar estos mundos híbridos, investigadores como 


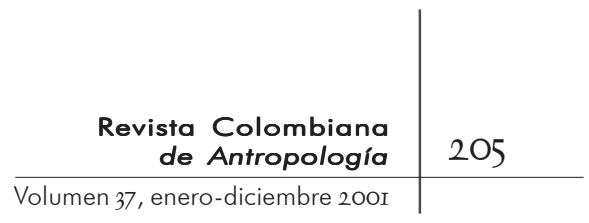

Oelshlaeger (I99I) han propuesto cambiar la oposición naturaleza/cultura por el concepto de salvaje -no domesticado- para identificar los espacios que están fuera del control humano. Algunos constructivistas radicales han propuesto analizar el medio ambiente dentro del texto cultural en el cual el primero tiene un papel pasivo, porque está bajo el simbolismo y la cultura. Sin embargo, de acuerdo con Descola y Pálsson (I996), estas perspectivas no proveen herramientas teóricas alternativas de una manera clara. Por esta razón, proponen trascender el dualismo al analizar los procesos y las relaciones que den cuenta de la diversidad de procesos de objetivación.

Descola (I996) considera que las nociones occidentales no pueden explicar diferentes ideas y relaciones entre humanos y entidades no humanas. Sin embargo, destaca que los antropólogos pueden describir las concepciones específicas que tienen diferentes culturas sobre la naturaleza. Para desarrollar esta perspectiva, estas descripciones deben surgir de las configuraciones, ideas y prácticas locales, al igual que de los conceptos que los locales tengan acerca de sí mismos y de los otros. Descola también destaca que al encontrar los patrones de significados o los esquemas de prácticas, los antropólogos pueden llegar a entender los modos de relaciones que éstos tienen con las entidades no humanas. Por tanto, propone "un modelo transformacional que dé cuenta de los esquemas implícitos de prácticas por medio de los cuales cada sociedad objetiviza tipos específicos de relaciones con su medio ambiente” (Descola y Pálsson, I996: I7). Para Descola:

Cada variación local es el resultado de combinaciones particulares de tres dimensiones básicas de la vida social: modos de identificación o el proceso por el cual las fronteras ontológicas son creadas y objetivizadas en sistemas cosmológicos tales como el animismo, el totemismo o el naturalismo; los modos de interacción que organizan la relación entre y en las esferas de los humanos y los no humanos de acuerdo con principios de reciprocidad, depredación o protección; y los modos de clasificación -básicamente esquemas metafóricos y metonímicos- por medio de los cuales los elementos básicos del mundo son representados como categorías socialmente reconocidas (Descola y Pálsson, I996: 17).

Pálsson propone usar el paradigma que ella denomina comunitario, que rehusa la "separación de la naturaleza y la sociedad 
y las nociones monológicas y de certeza, enfatizando en cambio la contingencia y el diálogo" (I996: 72). Esta perspectiva implica ir mas allá del individuo para centrarse en "la totalidad de la persona en acción, actuando en contextos de su actividad" (73). En este sentido, los humanos y el medio ambiente son vistos en un proceso de interrelación y reciprocidad. Además, esta perspectiva implica partir del conocimiento local como una manera de entender estas relaciones.

Desde la etnoecología se ha hecho un replanteamiento de la dicotomía sociedad/naturaleza, al partir no sólo de las concepciones locales para entender las relaciones entre "organismos y la totalidad de factores físicos, biológicos y sociales con los que entra en contacto" (Gragson y Blount, I999: VII). Así mismo, la etnoecología explora las perspectivas sobre la naturaleza de acuerdo con las situaciones particulares -posición e intereses de género, edad, especialización, etcétera- de los diferentes individuos y la manera como éstas se articulan para la toma de decisiones, acceso y control del entorno. Posiciones e intereses que establecen relaciones particulares con el entorno al transformarlo. De esta manera, el conocimiento local se plantea como central en procesos ecológicos y ecosistémicos. Por otro lado, la etnoecología abre posibilidades para que sean los mismos pobladores locales quienes generen este conocimiento. En general, los replanteamientos sobre las concepciones naturaleza/cultura a la luz de los sistemas locales buscan la generación de conocimientos específicos de acuerdo con situaciones particulares.

Sin embargo, los cambios en las concepciones y las categorías tienen implicaciones políticas; por lo tanto, es necesario explorar cómo las prácticas locales relacionadas con el medio ambiente y la naturaleza están siendo resignificadas o transformadas. La interrelación de diferentes nociones sobre la naturaleza implica también procesos de negociaciones y conflictos sobre su significado, el cual es político. De igual manera, supone que, por ejemplo, los cambios ambientales no sean neutros y que el acceso, los beneficios y costos de los recursos naturales sean mediados por relaciones desiguales de poder. Así mismo, es necesario entender las interrelaciones que estas prácticas tienen con procesos locales, regionales, nacionales y transnacionales y con procesos de acceso, control y derechos sobre los recursos.

Me centraré en la ecología política por considerar que ha brindado importantes elementos conceptuales que permiten entender 


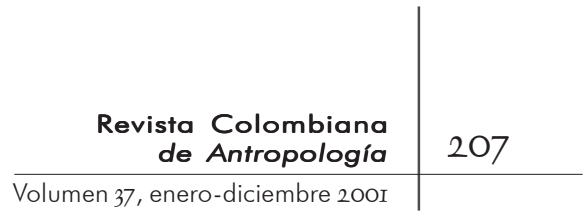

mejor los procesos relacionados con el medio ambiente en una dimensión política. Así mismo, porque esta perspectiva ha alimentado la ecología política antropológica y la antropología del ambientalismo (Little, 1999).

\title{
La ecología política y su relación con la antropología
}

\begin{abstract}
A FINALES DE LA DÉCADA DE I960 Y COMIENZOS DE LA DE I97O, DESArrollos en la ecología cultural y en la geografía del desarrollo, unidos a la introducción de las nuevas perspectivas de la economía política en los análisis del uso del medio ambiente permitieron el inicio y desarrollo de la ecología política, que estuvo relacionada con el surgimiento de la conciencia ecológica en los sesenta y con la proliferación de nuevos campos de investigación en lo ambiental -economía, historia, manejo, política y sociología con énfasis en lo ambiental, al igual que la ecología global-. El término de ecología política fue acuñado por Eric Wolf (I972) en su artículo "Ownership and political ecology”. Wolf exploró cómo el uso de la tierra y su impacto ecológico podía ser explicado al analizar la interrelación de los procesos locales con los procesos económicos y políticos a gran escala. El primer significado de la ecología política estaba relacionado con la interrelación del uso que los humanos dan a los recursos y el medio ambiente en términos del propósito social que esto implicaba. Los estudios en ecología política empezaron a analizar las estructuras políticas, sociales y económicas en relación con las decisiones de uso de los recursos (Peet y Watts, I996; Bryant y Bailey, I997; Painter, 1995).

De acuerdo con Bryant y Bailey (1997), durante los años 1970 los cambios ambientales globales trajeron a la ecología política nuevas discusiones y perspectivas. Para ese entonces, la ecología política tenía dos asociaciones diferentes: una relacionada con la perspectiva neo-malthusiana, y otra relacionada con la izquierda radical y el socialismo. Estas dos tendencias eran contradictorias y previnieron mayores desarrollos durante esa década. De hecho, los neo-malthusianos predecían una hecatombe ambiental debido al aumento de la población, lo que de acuerdo con ellos requería de políticas muy fuertes y un estado global
\end{abstract}




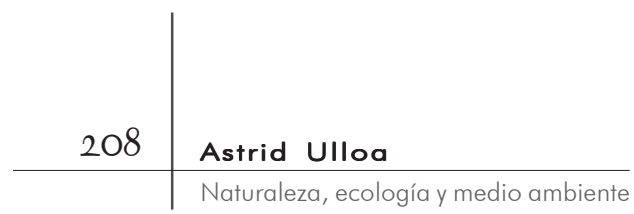

4. No es muy claro si Bryant y Bailey (1997) proponen como ecología política del tercer mundo los análisis que se han centrado en los problemas de los países del tercer mundo, o si ellos llaman de esta manera a los análisis realizados por académicos del tercer mundo. Algunos autores (Peet y Watts, I996; Escobar, I996; Moore, 1993; Durham, I995; Painter, I995) no hacen esta distinción. Investigadores del llamado tercer mundo que trabajan desde la perspectiva de la ecología política no han establecido un nombre particular para su enfoque. Por tanto, uso el nombre de ecología política de manera genérica, y sólo me referiré a la ecología política del tercer mundo para mencionar el trabajo de Bryant y Bailey.

autoritario. Esta perspectiva política fue criticada por la izquierda. Solamente hasta finales de los setenta y comienzos de los ochenta comenzó a surgir una nueva ecología política como resultado de la convergencia de la ecología política radicalizada y el socialismo. Durham (I995b) considera que sólo en los ochenta empezó la verdadera ecología política. Bryant y Bailey (I997) consideran que, de una manera paralela, durante los setenta y comienzos de los ochenta surgió lo que ellos llaman "la ecología política del tercer mundo"4.

La ecología política comenzó analizando las conexiones entre lo político y el cambio ambiental, al igual que criticando la perspectiva neo-malthusiana. Los primeros trabajos en ecología política (Watts, I983; Bunker, I985; Blaikie, I985; Collins, I987; DeWalt, I985; etcétera) se centraron en cómo mecanismos económicos y políticos de múltiples niveles -tales como organizaciones internacionales de desarrollo y políticas de corporaciones multinacionales- definían las condiciones sociales y los procesos de producción que afectaban el acceso y uso de los recursos y, por extensión, las condiciones ambientales (Bryant y Bailey, I997; Collins, i987; Edelman, I995; Stonich, I995; Painter, I995; Durham, I995a, I995b; Peet y Watts, I996).

Al final de los ochenta, diferentes investigadores (Blaikie, I985; Blaikie y Brookfield, I987; Guha, I989; Peet y Watts, I996; Stonish, I985; Jones, I990, I99I, 1995) introdujeron análisis de las relaciones de poder, género y etnicidad para entender los procesos de control y acceso a los recursos naturales. Estos estudios ofrecían explícitamente análisis históricos y contextuales de las relaciones entre la naturaleza y la sociedad en diferentes escalas, lo que implicaba la inclusión de diferentes actores, percepciones, explicaciones y sus intervenciones. Además, empezaron a introducir las negociaciones, los conflictos y, lo más importante, los procesos de resistencia. De esta manera, los nuevos actores sociales y su capacidad de acción comenzaron a ser aspectos centrales en los análisis relacionados con el medio ambiente.

Las perspectivas actuales en la ecología política están articuladas en torno a problemáticas globales -la crisis ambiental, las 


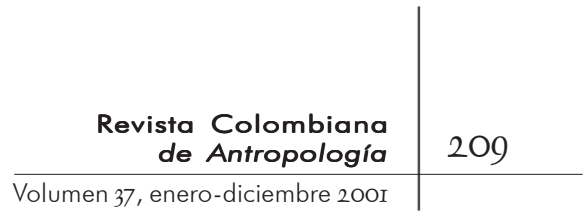

desigualdades demográficas y económicas-, discusiones teóricas posmarxistas, investigaciones centradas en la capacidad de acción de los actores sociales e intereses posestructuralistas por entender la relación poder/conocimiento. Las actividades políticas en torno al medio ambiente y los recursos naturales están relacionando diferentes y nuevos actores sociales -desde los movimientos sociales hasta las instituciones multilaterales- lo que implica análisis más complejos de los diversos niveles de interrelación, al igual que de los conflictos y las resistencias que implica la relación entre humanos y medio ambiente. Más aún, desarrollos en las perspectivas teóricas sobre los movimientos sociales, en la ecología política y en los análisis de discursos posestructuralistas permiten situar lo político más central que nunca al analizar las implicaciones políticas de los significados y los procesos de construcción del conocimiento, lo que permite una crítica de las construcciones modernas tales como el desarrollo, la naturaleza, la democracia, la sostenibilidad y lo político. De esta manera, la ecología política tiene el potencial para confrontar las políticas de las actuales concepciones hegemónicas ambientales (Peet y Watts, I996; Santos, I998).

De acuerdo con Bryant y Bailey (I997), las tendencias que en general caracterizan los estudios actuales de la ecología política son: I) Los cambios ambientales -la erosión, la deforestación tropical, la contaminación de las aguas, la degradación de la tierra, etcétera- (Durham, I995a, I995b; Painter, I995; Stonich, I995; Zimmerer, 1996); 2) Análisis de discursos sobre el desarrollo, las políticas forestales, los peligros naturales y el desarrollo sostenible, etcétera (Escobar, 1996; Sachs, 1992; Peet y Watts, I996; Pelusso, I992; Moore, I993, I996; Yapa, I996; Zimmerer, I996); 3) Análisis centrados en regiones geográficas específicas y en conflictos sobre acceso a los recursos ambientales (Moore, I996; Collins, I987); 4) Énfasis socioeconómico en clase, género y etnicidad (Pelusso, I995; Colchester, I993; Bebbington, I996); y 5) Actores sociales y sus interrelaciones por medio de su capacidad de acción (Bryant, 1992; Bryant y Bailey, 1997). Algunos investigadores (Escobar, I998; Yapa, 1996; Bebbington, I996) están desarrollando una perspectiva diferente, que se centra específicamente en las políticas y concepciones ambientales de los movimientos sociales. Ellos ponen énfasis en las propuestas ecológicas de los movimientos sociales como alternativas a los actuales regímenes ambientales. 
Los análisis de la ecología política con una perspectiva antropológica y etnográfica (Moore, I993, 1996, 1997) permiten un acercamiento cuidadoso a cómo se están dando, en lugares específicos, las construcciones culturales y ambientales, los conflictos, las luchas y los consensos sobre los significados y las prácticas ambientales. Por ejemplo, los estudios realizados por Moore (1996, 1997) en Zimbabwe presentan cómo los conflictos por el agua están traspasados por poder, significados culturales e intereses políticos de los diferentes actores.

Una perspectiva etnográfica sobre la micropolítica ambiental, acentuando lo significativo y lo material, también enfatizando la importancia de diferenciar el 'estado' y la 'comunidad', grupos de interés usualmente concebidos como monolíticos y vacíos de contestación interna (Moore, 1997: 26).

Estas perspectivas han alimentado los enfoques antropológicos, los cuales destacan el papel de las fuerzas sociales y su relación con el medio ambiente. Al igual que articulan los movimientos sociales, los derechos y accesos sobre los recursos y los territorios, y las políticas ambientales de cada sector social y los discursos ambientales, generando un enfoque que Little (I999) denomina la ecología política antropológica. Para realizar estos análisis se ha transformado la concepción de comunidad cerrada, para tener en cuenta los diferentes actores que están interrelacionados en lo ambiental.

Desde perspectivas de la ecología política -especialmente desde los enfoques sobre análisis de discursos, etnicidad, capacidad de acción de los actores sociales y ecología política de los movimientos sociales-, a continuación caracterizo, de manera general, el escenario político en el que están situados los diferentes actores sociales y sus políticas ambientales, en lo que Bryant y Bailey (I997) llaman un ambiente politizado. Análisis sobre la interrelación de estos actores son parte de la nueva perspectiva de la antropología con respecto a la relación socie$\mathrm{dad} /$ naturaleza. 


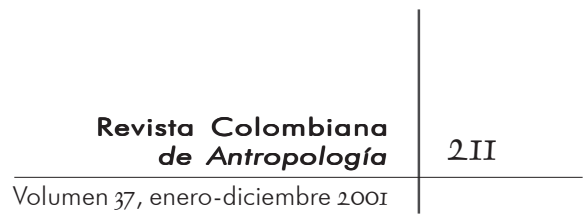

\section{Actores sociales interrelacionados en un ambiente politizado}

$\mathrm{U}$

TILIZO EL CONCEPTO DE “MEDIO AMBIENTE POLITIZADO" PROPUES-

to por Bryant y Bailey (I997), dado que describe cómo los problemas ambientales implican luchas sobre significados, que tienen consecuencias para los diversos actores sociales de acuerdo con contextos económicos y políticos particulares, locales, nacionales y globales. Un ambiente politizado implica que los problemas ambientales no son neutrales y que el acceso, los usos, beneficios y costos de los recursos naturales están mediados por relaciones desiguales de poder.

Bryant y Bailey (1997) consideran que hay cinco tipos de actores importantes dentro de las luchas ambientales: el estado, las instituciones multilaterales, las corporaciones transnacionales, las organizaciones no gubernamentales y las organizaciones de base. Sin embargo, considero que los dos últimos actores -las organizaciones no gubernamentales y las organizaciones de base- aunque muchas veces representan a los pobladores locales no expresan completamente las problemáticas que ellos tienen en relación con los cambios ambientales. Más aún, organizaciones no gubernamentales han ayudado a implementar programas de desarrollo que no tienen en consideración las concepciones locales sobre la naturaleza y el desarrollo. Por tanto, es importante llamar la atención sobre las diferencias que existen entre las ONG ambientalistas, dado que hacer una generalización impide ver las contradicciones que existen entre ellas, por sus intereses particulares. Por otro lado, en algunas ocasiones las organizaciones de base son la cara pública y política de los pobladores locales, pero muchas veces no están en relación directa y permanente con los mismos. Por tanto, aunque parto de las cinco categorías de Bryant y Bailey, considero que deben afinarse un poco más. Propongo entonces cambiar la categoría de organizaciones de base por la de movimientos sociales, ya que esta última permite la inclusión de un rango mayor de actores tales como los movimientos ambientales, los movimientos indígenas y las mismas organizaciones de base. Dentro de la categoría de actores locales se incluye a las diversas personas -líderes comunitarios, autoridades locales y diversos miembros de la comunidad de acuerdo con género, edad, prestigio, etcétera- que tienen autoridad sobre los asuntos ambientales en el ámbito local. Así, en un ambiente politizado 


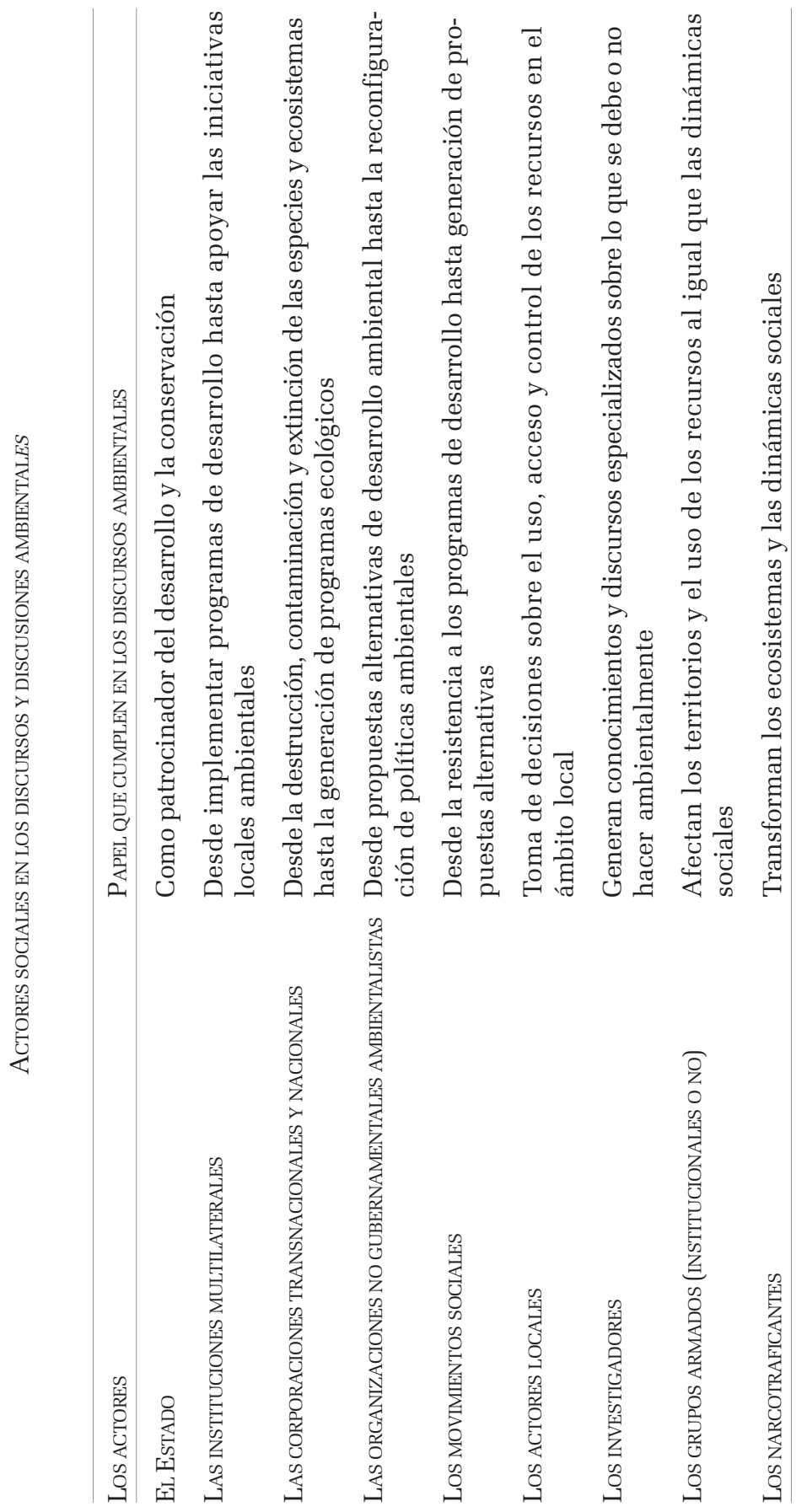




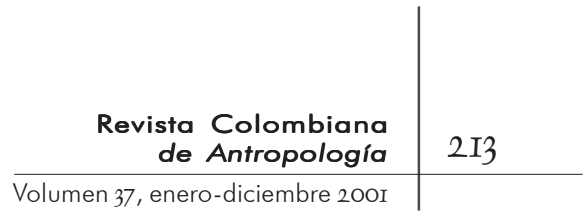

se transforman los estereotipos sobre los pobladores locales como nativos inmersos en una naturaleza prístina y se ubican como agentes políticos.

De igual manera, considero que deben incluirse otros actores tales como los investigadores -locales o no-, quienes influyen procesos de toma de decisiones y ayudan a la construcción de discursos en torno al medio ambiente, la ecología y la naturaleza, al discutir las implicaciones científicas de las acciones que lo afectan. Estos actores conforman las llamadas "comunidades epistémicas" (Haas, 1989, I992) dado que comparten creencias y acciones políticas, en este caso en relación con los cambios ambientales. Finalmente, es necesario destacar el papel de actores tales como grupos armados -institucionales o no- y narcotraficantes, quienes afectan no sólo los territorios y los recursos sino también las dinámicas sociales de los pobladores locales.

De acuerdo con Brysk (2000), estos actores están interrelacionados en diferentes esferas -dentro del estado, el mercado y la sociedad- lo que implica diversos tipos de relaciones -conflictivas, armónicas, etcétera-, resistencias e identidades, que median a estos actores y sus interacciones. Estas esferas de relaciones internacionales y nacionales implican intereses políticos, procesos sociales e instituciones sociopolíticas particulares. En el ámbito de lo ambiental, la presencia de estos múltiples actores implica una diversidad de discursos, posiciones y acciones muchas veces contradictorias no sólo entre actores sino entre discursos y acciones.

LA PROBLEMATIZACIÓN DE LO NATURAL, LO ECOLÓGICO Y LO AMBIENTAL en América latina

AS PERSPECTIVAS ANTROPOLÓGICAS DISCUTIDAS ANTERIORMENTE HAN alimentado las investigaciones realizadas en Latinoamérica y

Colombia, las cuales a su vez han creado sus propios enfoques de acuerdo con los paradigmas de los investigadores y de la situación particular de cada contexto nacional y grupo social con el que trabajan. Desde finales de los años I960 algunos investigadores comenzaron a realizar estudios etnográficos sobre las concepciones de naturaleza y el manejo de los recursos por 


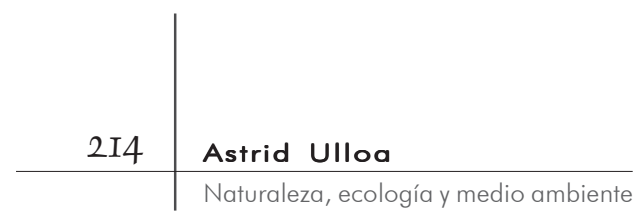

parte de los indígenas. Si bien en su inicio fueron análisis basados en el registro etnográfico y arqueológico sobre grupos específicos, actualmente hay trabajos interdisciplinarios con las ciencias naturales y diversos especialistas, lo que tiende a presentar de una manera compleja la interacción de estos grupos con su entorno y su relación con contextos regionales, nacionales y transnacionales.

$\mathrm{Al}$ analizar las imágenes de naturaleza y sociedad sobre la amazonia, Viveiros de Castro (I996) revisa los modelos conceptuales que han alimentado dichos estudios, que pueden generalizarse a los trabajos publicados más representativos que han abordado las relaciones humanos/naturaleza en América latina. Desde mediados de los años I940 hasta finales de la década de I95O se privilegiaba la perspectiva determinista ambiental de la cual el Handbook of South American Indians es un ejemplo (Steward, I946-I950; Steward y Faron, I959). En este panorama, en los años I960 irrumpe la tradición europea liderada por Claude Lévi-Strauss, dándose un mayor énfasis a las dimensiones sociales y simbólicas de las relaciones entre humanos y naturaleza. Así mismo, desde los sesenta las escuelas británica y estadounidense -que desarrollaron perspectivas desde la etnociencia y la antropología simbólica- se centraron en monografías sobre los sistemas cosmológicos de los grupos indígenas. Sin embargo, estas diversas tendencias respondían a lo que Viveiros de Castro (I996) denomina el modelo estándar en el que, por ejemplo, los grupos amazónicos eran descritos como aislados, autónomos, autosuficientes e igualitarios. Bajo este modelo, la tradición de la ecología cultural privilegiaba el determinismo ambiental, mientras que los antropólogos sociales se centraban en la complejidad de los procesos culturales (Viveiros de Castro, I996). Lo que partía de una noción de naturaleza externa y prístina.

Sin embargo, cabe destacar los trabajos de Gerardo ReichelDolmatoff (I967) desde 1967, en los que a partir del contexto colombiano clamaba por la necesidad de investigaciones etnoecológicas con una perspectiva diferente. Así, la etnoecología, tema recurrente en los escritos de Reichel-Dolmatoff, presenta un aporte único al destacar la cosmología y los procesos simbólicos en la interacción entre los indígenas con su medio ambiente, en los que los flujos de energía -de fuerzas femeninas y masculinas-consumidas y producidas afectan todo el universo, lo que implica un reajuste permanente para mantener el balance 


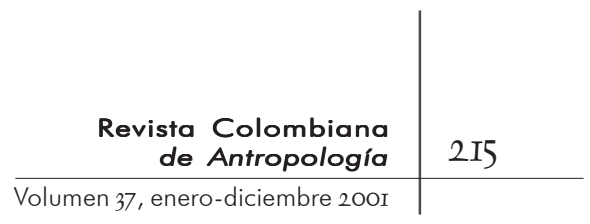

energético ambiental y social. Esta perspectiva influyó la mirada de diversos investigadores, cuyos análisis etnoecológicos destacan los procesos de interacción de las energías presentes en la cosmovisión y sus efectos en las prácticas de manejo del entorno por parte de los indígenas (Pineda, 1999).

De igual manera, desde los años 1970 y 1980, en las investigaciones etnoecológicas lideradas por Descola (I989), Baleé (I988), Posey et al., (I982); Schultes y Raffauf (I990), entre otros, se plantea partir de las categorías y los contextos particulares de cada grupo social, destacando los conocimientos ecológicos de los grupos indígenas y su papel en la transformación y construcción de sus entornos. Paralelamente, se destacan los análisis sobre los sistemas indígenas y campesinos de conocimiento, articulados al conocimiento científico para generar propuestas de desarrollo rural acordes con los contextos locales y de manera participativa (desarrollo rural participativo, Altieri y Yurjevic, I99o). Esta perspectiva planteó la dimensión política a las investigaciones etnoecológicas y un lugar a los conocimientos sobre el entorno y el manejo dado a sus recursos por parte de los grupos locales (Reichel, 1995).

Estos enfoques permitieron desbordar el modelo estándar. De acuerdo con Viveiros de Castro (1996), el modelo estándar también se replanteó para el Amazonas gracias a los estudios arqueológicos sobre las poblaciones indígenas antes de la Conquista, los cuales reconsideran las estimaciones sobre el porcentaje de pobladores y la complejidad de las sociedades. Esto ligado a las discusiones teóricas sobre el concepto de sociedad y parentesco y al replanteamiento de las dicotomías conceptuales entre naturaleza/cultura permitió traspasar el modelo estándar y generar nuevas perspectivas en los análisis sobre los humanos y sus relaciones con el entorno, a la luz de nuevas perspectivas de la ecología humana, la historia, la antropología social y la etnoecología (Viveiros de Castro, I998).

Desde finales de los años I980 y en la década de I990, la crisis ambiental global, la propuesta de un desarrollo sostenible y las políticas de conservación ambiental han abierto el espacio para la discusión sobre la diversidad biológica y la revalorización de la diversidad cultural, los sistemas de conocimiento, las prácticas y el manejo del medio ambiente por parte de los grupos étnicos. De esta manera, se enfatiza la importancia de los conocimientos locales y su relación con la biodiversidad. Esto se ha 
visto reflejado en los trabajos interdisciplinarios adelantados por antropólogos en el campo de la etnoecología y etnobiología (Toledo, 1989; Altieri y Yurjevic, I990; Posey, I990; Moran, I993; Pineda, I999; Ulloa et al., I996). Paralelamente, se han iniciado trabajos en los que se reflejan las dinámicas y las propuestas de los movimientos sociales, lo que supone una mirada a las implicaciones políticas que tienen los programas de desarrollo sostenible y la posibilidad de generación de desarrollos alternativos basados en los conocimientos locales.

De esta manera, las nuevas perspectivas centran sus análisis en la diversidad ambiental y su relación con las actividades humanas. En estos enfoques la naturaleza es resultado de procesos históricos culturales, en los que se privilegian las prácticas de subsistencia y las estrategias de manejo de los recursos naturales por parte de grupos locales. Así mismo, los grupos sociales son vistos desde su complejidad sociopolítica y en su interrelación con diversos actores sociales en el ámbito local, nacional y global.

\section{Tendencias en la investigación antropológica sobre naturaleza, ecología y medio ambiente en Colombia}

工 n colombia los estudios antropológicos acerCa de las RELAcada vez más, generando varias tendencias de investigación las cuales se resumen de manera general en temáticas en torno as:

- La sistematización y descripción de los sistemas de conocimiento de grupos étnicos y comunidades locales sobre lo ambiental, buscando los modelos que rigen las relaciones entre humanos y su entorno. En este caso se ana-

5. Se mencionan solamente algunos de los trabajos publicados como ejemplo de las tendencias, sin desconocer que hay gran cantidad de publicaciones sobre el tema al igual que varios autores que tienen perspectivas particulares o que combinan varias de las tendencias propuestas. lizan las conceptualizaciones sobre el ser humano, el medio ambiente y el territorio (Reichel-Dolmatoff, I968, I976, I978, I996; Von Hildebrand, 1983; Reichel, I989; Correa, I990; Van der Hammen, I992; Ulloa, I996; Escobar, I998; Restrepo, I996; Osborn, I995; Pineda, I990; Århem, I990; Nieto, I989; Echavarría, I994; Vasco, 1990). Esta perspectiva analiza, 


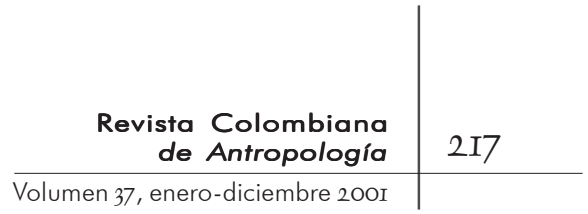

por ejemplo, cómo las sociedades indígenas y afrocolombianas, y los grupos campesinos establecen una cosmología y ecología particular sobre su entorno, socializan la naturaleza y manejan categorías temporales y espaciales que plantean una concepción no occidental de la naturaleza. Análisis particulares sobre etnobotánica y etnozoología (La Rotta, I983; Garzón y Macuritofe, I990; Turbay et al., 1999; Turbay, I994; Rubio, et al., I998; Cárdenas y Politis, 2000) discuten las clasificaciones que hacen algunos grupos sociales de su entorno. Algunos de estos trabajos articulan los análisis con las descripciones y percepciones que los propios actores locales hacen de sus concepciones. Sin embargo, varias de estas investigaciones se concentran en la lógica misma de los sistemas de conocimiento y muchas veces no consideran aspectos más generales y contextos más amplios de interacción entre los humanos con el entorno.

- Las perspectivas individuales y su incidencia en la relación de los seres humanos con su entorno han empezado a ser una preocupación de varios investigadores. Estos análisis buscan contextualizar las visiones y situaciones particulares de los individuos de acuerdo con, por ejemplo, el género y su incidencia en el uso, acceso y control de los recursos (Camacho, 1998, I999). Sin embargo, faltan trabajos que profundicen sobre los procesos de toma de decisiones y sobre la diversidad de los que existen en el ámbito de la familia, la comunidad o el grupo social.

- La identificación de estrategias de manejo de ecosistemas y especies por parte de grupos sociales contemporáneos y pasados (Van der Hammen, 1992; Ulloa et al., 1996; Falchetti, 1994; Cavelier y Mora, I995). En estos análisis se plantean historias ambientales de zonas particulares y se establecen los posibles modelos de manejo ambiental de ecosistemas, recursos o especies, evaluando la dimensión ecológica que éstos tienen.

- Análisis sobre las formas de representar el medio ambiente por medio de la cultura material, expresadas en lo iconográfico, lo musical y lo oral, entre otras (Legast, i986; Turbay et al., I999; Turbay, I994; Falchetti, I994; Reichel-Dolmatoff, I988). Allí se destacan los aspectos formales de las relaciones de los humanos con los animales.

- La productividad de los sistemas agrícolas, la recolección, la 
cacería y su aporte a las concepciones de desarrollo sostenible y a la conservación. En estos análisis se tiende a examinar el uso de recursos y a comprender la economía de las selvas tropicales y lugares biodiversos a partir de las prácticas locales. Esta tendencia está ligada a los programas ambientalistas de las ONG en los que los investigadores -antropólogos y biólogos, entre otros- relacionan estas investigaciones con la producción sostenible de mercancías verdes y ecoturismo. En este caso se busca posicionar, empoderar a los actores locales y encontrar mejores estrategias de participación para la comercialización de los productos mediante la certificación cultural y ambiental. Si bien esta tendencia no es liderada directamente por investigadores ni por el campo netamente académico, sí son espacios de trabajo de gran cantidad de antropólogos dentro de las ONG (véanse los programas de la Fundación Inguede, de la Fundación Pro-Sierra Nevada de Santa Marta y de la Fundación Gaia, entre otros). Sin embargo, no hay análisis de los impactos que estos proyectos tienen sobre las prácticas, economías y conceptualizaciones locales, ni de los ciclos que tiene la producción y el consumo de eco o etno-mercancías.

- Los impactos ambientales y sociales de los programas de desarrollo (Duque et al., I997; Turbay, I997; Ángel et al., I997), los cuales buscan evaluar y mitigar los efectos que tienen los proyectos de desarrollo -minas, proyectos hidroeléctricos, petróleo, carreteras, bases militares, etcétera- sobre grupos particulares. Así mismo, en estos trabajos se plantean metodologías y recursos técnicos para evaluar dichos impactos. A partir de esta perspectiva se propone una antropología aplicada con énfasis en proyectos de desarrollo. En consecuencia, se plantean estrategias para que se articulen las propuestas de desarrollo con la conservación ambiental y la situación cultural de los pobladores afectados. Paralelamente, hay antropólogos que han venido trabajando en la antropología para el desarrollo en los programas de instituciones gubernamentales -Desarrollo Rural Integrado, DRI, Red de Solidaridad, Plan Nacional de Rehabilitación, PNR, entre otras- y no gubernamentales, pero sobre estos trabajos no hay muchas reflexiones conceptuales.

- Los derechos colectivos del territorio, de los recursos naturales y de propiedad intelectual. En los últimos años se ha generado 


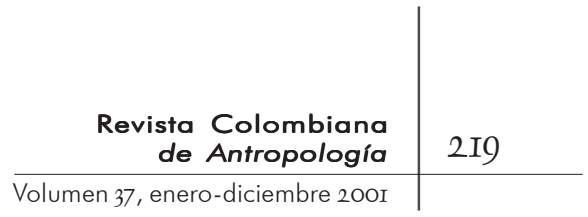

un trabajo interdisciplinario entre antropólogos, biólogos y abogados que realizan análisis críticos de los impactos que traen la crisis ambiental y los procesos y las políticas ambientales, nacionales e internacionales -Convenio de diversidad biológica, creación de áreas protegidas, por ejemplo-sobre grupos sociales específicos y cómo estos afectan los derechos territoriales y de propiedad intelectual de estos actores sociales, caso específico la biopiratería y los grandes programas de extracción. En particular, en relación con la problemática de los parques naturales, los grupos locales y la biodiversidad se han venido desarrollando una serie de investigaciones y discusiones que replantean la noción de área protegida como espacio de preservación. Así mismo, plantean la generación de espacios de concertación entre los diferentes actores relacionados para la concertación y el manejo de los recursos a partir de los pobladores locales (Ulloa et al., I996; Flórez, 1998; Sánchez et al., 2000; Rubio et al., 2000).

- Las articulaciones entre los movimientos sociales y las políticas ambientales (Escobar, 1999; Ulloa, 200I). En dichos trabajos se realizan análisis amplios sobre los efectos que las acciones políticas de los movimientos sociales tienen en las discusiones nacionales e internacionales sobre el medio ambiente. De igual manera, se analizan las luchas políticas de dichos movimientos sociales por el derecho a sus territorios y recursos y sus propuestas político-ambientales.

- Análisis de los discursos del desarrollo y el medio ambiente (Escobar y Pedrosa, 1996), en los que de manera crítica se analizan las consecuencias ambientales y sociales que implica la idea del desarrollo económico y sostenible. Desarrollos de modelos conceptuales para abordar la problemática ambiental en Colombia (Escobar, I999; González, I996).

- Discusiones sobre las construcciones de las nociones de naturaleza (Serge, I999) y paisaje (Rozo, I999; Santoyo, I999; Castrillón, 1999) que buscan contextualizar el surgimiento e imposición de estas categorías por medio de los documentos científicos y de viajeros.

- Los desarrollos de la biotecnología y la genética. Aunque no está consolidado un grupo amplio de antropólogos que estén investigando estos aspectos, esta problemática plantea nuevas discusiones éticas y conceptuales sobre las relaciones de los humanos con lo natural, lo social y lo individual. 


\section{ReFLEXIONES FinAles}

A NATURALEZA COMO UNA CONSTRUCCIÓN SOCIAL ES UN CONCEPTO ahora bien reconocido. Por tanto, es evidente que diferentes L construcciones sobre la naturaleza pueden coexistir en un contexto social dado. De hecho, desde los años I97o han venido proliferando y ganando importancia diversas nociones sobre la naturaleza, la ecología y el medio ambiente -desde una naturaleza prístina a los cuasi-objetos o cyborgs- como resultado del surgimiento de los movimientos ambientalistas, los movimientos indígenas, el surgimiento de la conciencia ambiental e investigaciones en el ámbito social y natural que reconocen dichas concepciones.

Todas estas nuevas discusiones han influenciado la antropología cultural, la antropología ecológica, la sociobiología y la etnoecología, lo que ha llevado a que se reconsideren las nociones centrales sobre la naturaleza. De manera similar, la ecología y el medio ambiente son nociones que se han venido transformando hasta situar las relaciones entre humanos y no humanos a partir del conocimiento local y dentro de un contexto amplio en el ámbito político, económico y social. Las tendencias recientes de investigación en la antropología sobre asuntos relacionados con el medio ambiente requieren de un trabajo interdisciplinario que articule la perspectiva antropológica con otras disciplinas -biología de la conservación, manejo de recursos, geografía humana, psicología e informática, entre otras-. Esta perspectiva interdisciplinaria articula estudios empíricos con análisis críticos de las relaciones entre humanos y medio ambiente. Así mismo, hay un acuerdo general para explorar las nociones de naturaleza como construcciones sociales, siendo necesario interrelacionar, en una perspectiva histórica, nuevas concepciones sobre cuerpo, género, etnicidad y relaciones entre individuo/medio ambiente, y los sistemas locales de conocimiento.

Explorando en las perspectivas y tendencias presentadas anteriormente, considero que en Colombia hay necesidad de analizar las políticas, prácticas, percepciones, representaciones y significados de pobladores locales -grupos étnicos y comunidades localesrelacionados con la naturaleza y el medio ambiente a partir de la ecología política -con una perspectiva etnográfica-, al igual que de abordar nuevas perspectivas antropológicas sobre las construcciones sociales en torno a la relación naturaleza/cultura. La 


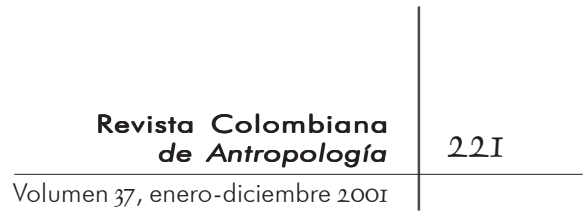

ecología política necesita explorar concepciones locales y no occidentales sobre naturaleza/cultura para entender otras concepciones y prácticas sobre la naturaleza y sus interrelaciones con las políticas ambientales locales y globales. La antropología contribuye a esta perspectiva al situar las concepciones, percepciones, representaciones, significados y prácticas de los indígenas, campesinos y diversas culturas de una manera compleja, en las políticas ambientales locales, regionales, nacionales y globales.

Sin embargo, debe tenerse en cuenta que hay perspectivas teóricas que tienden a situar las prácticas locales como una interacción completamente armónica entre la naturaleza y la cultura, lo que continúa reafirmando la concepción moderna de la naturaleza. De esta manera, los pobladores locales se presentan en constante reciprocidad con los recursos naturales, en oposición a las sociedades occidentales industrializadas, las cuales actualmente tienen un uso irracional de los recursos naturales, muchas veces desconociendo o esencializando las concepciones o prácticas locales. Además, cuando se describen las prácticas locales y del uso y manejo que dan a los recursos, se tiende a idealizarlas y a presentarlas bajo la lógica de la perfecta racionalidad de uso -los locales usan los recursos de una manera óptima pero sin explotarlos-.

De esta manera, se reafirma la visión moderna de naturaleza, al describir un Occidente caótico como resultado de los procesos de industrialización, contaminación y polución. Estas posiciones extremas pueden llegar a desconocer que existen y han coexistido múltiples nociones de naturaleza que responden a contextos históricos y sociales particulares. Por tanto, vale la pena preguntarse si las investigaciones antropológicas están reproduciendo las mismas categorías duales pero en una posición diferente-sociedad/naturaleza, modernidad/tradición, racional/ emocional y hombre/mujer-, dando realmente un espacio conceptual a otras nociones de naturaleza, o explorando cómo se construyen dichas categorías en contextos históricos y sociales particulares. 


\section{Bibliografía}

Altieri, M. y A. Yurjevic. I99o. Agroecología y desarrollo rural en América latina. Consorcio Latinoamericano de Agroecología y Desarrollo. Santiago.

Ángel, Enrique; Sergio Carmona y Luis Carlos Villegas. I997. Gestión ambiental en proyectos de desarrollo. Fondo FEN. Bogotá.

ÅrHEM, KAJ. 1996. "The cosmic food web: human-nature relatedness in the northwest Amazon". En Philippe Descola y Gisli Pálsson (eds.). Nature and Society. Anthropological Perspectives. Routledge. Londres.

I990. "Ecosofía makuna”. En La selva humanizada. Ecología alternativa en el trópico húmedo colombiano. François Correa (ed.): I09-I26. Instituto Colombiano de AntropologíaCerec. Bogotá.

BaleÉ, William. 1988. "Indigenous adaptation to Amazonian palm forests”. Principles 32 (2).

Bebbington, Anthony. 1996. "Movements, modernization and markets. Indigenous organizations and agrarian strategies in Ecuador”. En Richard Peet y Michael Watts (eds). Liberation ecologies. Environment, development, social movements. Routledge. Londres.

Behar Ruth y Deborah A. Gordon (EDs.). 1995. Women writing culture. University of California Press.

Blaikie, Piers y Harold Brookfield. 1987. Land degradation and society. Methuen. Londres.

Blaikie, Piers. 1985. The political economy of soil erosion in developing countries. Methuen. Londres.

Blatter, Joachim, Helen Ingram y Pamela Doughman. 200ia. "Emerging approaches to comprehend changing global contexts". En Joachim Blatter y Helen Ingram (eds.). Reflections on water: New approaches to transboundary conflicts and cooperation. The MIT Press. Londres.

Blatter, Joachim, Helen Ingram y Suzanne Levesque. 200ib. “Expanding Perspectives on Transboundary Water". En Joachim Blatter y Helen Ingram (eds.). Reflections on water: New approaches to transboundary conflicts and cooperation. The MIT Press. Londres.

Brosius, Peter. I999. "Analyses and Interventions. Anthropological Engagements with Environmentalism". Current Anthropology. Vol. 40, Number 3, June 1999. 


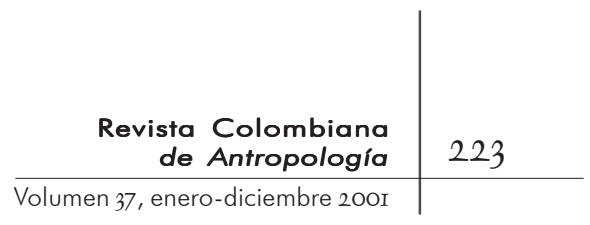

Bryant, Raymond y Sinead Bailey. 1997. Third world political ecology. Routledge. Londres.

BRyAnt, RAYMOND. I992. "Political ecology: an emerging research agenda in Third World studies". Political Geography II(I).

BRysk, Alison. 200o. From local village to global village: Indian rights and international relations in Latin America. Stanford University Press. Stanford.

BunKER, STEPHEN. I985. Underdeveloping the Amazon. University of Illinois Press. Chicago.

Burton, Michael y Douglas White. 1984. "Sexual division of labor in agriculture”. En American Anthropologist 86(3), September.

CamaCho, Juana. 1998. "Mujeres negras y biodiversidad: importancia de las prácticas femeninas de cultivo en espacios domésticos en el Pacífico chocoano". En Informes antropológicos. $\mathrm{N}^{\circ}$ 9: 69-80. ICAN. Bogotá.

1999. "Todos tenemos derecho a su parte: derechos de herencia, acceso y control de bienes en comunidades negras de la costa pacífica chocoana”. En J. Camacho y E. Restrepo (eds.). De montes, ríos y ciudades: territorios e identidades de la gente negra en Colombia. Fundación Natura-Ecofondo-ICAN. Bogotá.

CAVEliER, InÉS y SANTIAgo Mora. I995. Ámbito y ocupaciones tempranas de la América tropical. Fundación Erigaie.

Cárdenas, Dairon y Gustavo G. Politis. 2000. "Territorio, movilidad, etnobotánica y manejo del bosque de los nukak orientales. Amazonia colombiana". Estudios antropológicos $\mathrm{N}^{\circ}$ 3. Universidad de los Andes. Bogotá.

Castrillón, Alberto. i999. "La naturaleza del paisaje". En Revista de Antropología y Arqueología. Vol iı. No. i-2. Universidad de los Andes. Facultad de ciencias sociales. Departamento de antropología. Bogotá.

Colchester, Marcus. 1993. "Prates, squatters and poachers: the political ecology of dispossession of the natives people of Sarawak". Global Ecology and Biogeography Letter 3(4-6).

Collins, JANe L. I987. "Labor scarcity and ecological change". En P. D. Little, M. M. Horowitz y A. E. Nyreges (eds.). Lands at risk in the third world: local level perspectives.

CoRrea, FrançoIs (ED.). I99o. La selva humanizada. Ican-Cerec. Bogotá.

Cronon, William. 1995. "Uncommon ground. Toward reinventing nature". En Search of nature. W. W. Norton and Company. Nueva York. 
Descola, Philippe y Gisli Pálsson (eds). i996. Nature and society. Anthropological perspectives. Routledge. Londres.

Descola, Philippe. 1996. "Constructing natures: symbolic ecology and social practice”. En Descola Philippe y Gisli Pálsson (eds.). Nature and society. Anthropological perspectives. Routledge. Londres.

1994. En The society of nature: A native ecology in Amazonia, trans. Nora Scott. Cambridge University Press. Cambridge. I989. La selva culta. ABYA-YALA. Quito.

DeWalt, Billie. I985. "Microcosmic and macrocosmic processes of agrarian change in Southern Honduras: The Cattle are eating the Forest”. En DeWalt, Billie y P.J. Pelto (eds.). Micro and Macro Levels of Analysis in Anthropology. Westview Press.

Di Leonardo, Micaela (ed.). ig9i. Gender at the crossroads of knowledge. University of California Press.

Durham, Michael. I995a. "Anthropological perspectives on environmental destruction”. En Michael Painter y William H. Durham (eds.). The social causes of environmental destruction in Latin America. The University of Michigan Press.

I995b. "Political Ecology and Environmental Destruction in Latin América”. En Michael Painter y William H. Durham (eds.). The social causes of environmental destruction in Latin America. The University of Michigan Press.

Duque, luz Marcela; Iván Darío Espinosa, Aída Cecilia Gávez, Diego Herrera y SANDra Turbay. I997. "Chajeradó, el río de la caña flecha partida. Impacto sociocultural de la explotación de madera sobre un grupo embera del Atrato medio antioqueño". Instituto Colombiano de Cultura-Colcultura. Bogotá.

Dwyer, Peter. 1996. "The invention of nature”. En Ellen, Roy y Katsuyoshi Fukui (eds.). Redefining Nature. Ecology, Culture and Domestication. Berg. Oxford.

Echavarría, Cristina. i994. "Cuentos y cantos de las aves wiwa”. En Boletín del Museo del Oro. 37: 2-33. Banco de la República, Bogotá.

EDELMAN, MARC. I995. "Rethinking the hamburger thesis: Deforestation and the crisis of central America's Beef Exports”. En Michael Painter y William H. Durham (eds.). The social causes of environmental destruction in Latin America. The University of Michigan Press.

Ellen, Roy y Katsuyoshi Fukui (eds.). 1996. Redefining nature. Ecology, culture and domestication. Berg. Oxford. 


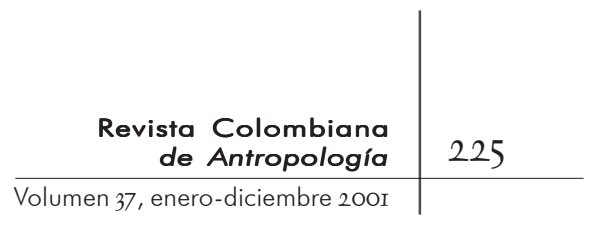

ElLEN, Roy. 1996a. "Introduction". Ellen, Roy y Katsuyoshi Fukui (eds.). Redefining nature. Ecology, culture and domestication. Berg. Oxford.

1996b. "The cognitive geometry of nature: a contextual approach”. En Descola Philippe y Gisli Pálsson (eds.). Nature and society. Anthropological perspectives. Routledge. Londres.

Escobar, Arturo. I999. El final del salvaje. Naturaleza, cultura y política en la antropología contemporánea. ICAN-Cerec. Bogotá.

I998. "Whose Knowledge, Whose Nature? Biodiversity, conservation, and the political ecology of social movements". Journal of Political Ecology. Vol. 5.

1996. "Constructing nature. Elements for a poststructural political ecology". En Richard Peet y Michael Watts (eds.). Liberation ecologies. Environment, development and social movements. Routledge. Londres.

Escobar, Arturo y Álvaro Pedrosa (editores). I996. Pacífico: ¿desarrollo o diversidad? Cerec. Bogotá.

Falchetti, Ana María. i994. El oro del Gran Zenu. Metalurgia prehispánica en las llanuras del Caribe colombiano. Banco de la República. Bogotá.

Fisher, WiLliam. 1995. Toward sustainable development. M.E. Sharpe. Londres.

Flórez, Margarita (editora). I998. Diversidad biológica y cultura. Retos y propuestas desde América Latina. Ilsa-Idea-WWF. Bogotá.

García, María. i992. “The Venezuelan ecology movement”. En Arturo Escobar y Sonia Álvarez (eds.). The making of social movements in Latin America. WestviewPress.

Garzón, Cristina y Vicente Macuritofe. I990. "La noche, las plantas y sus dueños: una aproximación al conocimiento botánico de una cultura amazónica”. Corporación Araracuara. Bogotá.

Gragson Ted y Ben G. Blount (eds.). I999. Ethnoecology. Knowledge, resources and rights. University of Georgia Press. Athens-Londres.

GuHa, Ramachandra. I989. The unique woods: Ecological change and peasant resistance in the Himalaya. Oxford University Press.

Haas, Peter. 1989. "Do regimes matter" Epistemic communities and Mediterranean pollution control". International Organisation. Vol. $43, \mathrm{~N}^{\mathrm{O}} 3$ Summer.

1992. "Introduction: Epistemic communities and international policy coordination". International Organisation Vol. 46, N ${ }^{\circ}$ I, Winter. 
Haraway, Donna. I988. "Situated knowledges: The science question in feminist as a site of discourse on the privilege of partial perspective”. Feminist Studies i4 (3).

- 199I. Simians, cyborgs and women: The reinvention of nature. Routledge. Nueva York.

Harris, Marvin. 1966. "The cultural ecology of India's sacred cattle”. Current Anthropology 7: 51-66.

HJort, A. I982. "A Critique of "Ecological" Models of Pastoral Land Use". Nomadic Peoples Io.

INGOLD, Tiм. I996a. "Hunting and gathering as ways of perceiving the environment". En Roy Ellen y Katsuyoshi Fukui (eds.). Redefining nature. Ecology, culture and domestication. Berg. Oxford.

I996b. "The optimal forager and economic man". En Descola Philippe y Gisli Pálsson (eds.). Nature and society. Anthropological perspectives. Routledge. Londres.

Jones, JAmEs C. 1990. A Native Movement and March in Eastern Bolivia Rationale and Response. Institute for Development Anthropology Network 8 (2).

1991. Economics, Political Power, and Ethnic Conflict on a Changing Frontier: Notes from the Beni Depart, Eastern Bolivia. Working Paper $\mathrm{N}^{\mathrm{o}}$ 58. Binghamton. Institute for Development Anthropology. Nueva York.

1995. "Environmental Destruction, Ethnic Discrimination, and International Aid in Bolivia". En Michael Painter y William H. Durham (eds.). The Social Causes of Environmental Destruction in Latin America. The University of Michigan Press.

Klandermans, Bert y Sidney Tarrow. I988. "Mobilization into Social Movements: Synthesizing European and American Approaches". En International Social Movement Research: A Research Annual, Volume I.

Kuclin, HenriKa. I996. "After Ishmael: The Fieldwork tradition and its future". En Akhil Gupta y James Fergusson (eds.). Anthropological Locations: Boundaries and Grounds of a Field science. CA: University of California Press. Berkeley.

La Rotta, Constanza. I993. Observaciones etnobotánicas sobre algunas especies utilizadas por la comunidad indígena Andoque. Corporación Araracuara. Bogotá.

LATOUR, BRUNo. 1993. We have never been modern. Harvard University Press. Cambridge, Massachusetts.

Legast, Anne. 1986. El animal en el mundo mítico tairona. Banco de La República, Bogotá. 


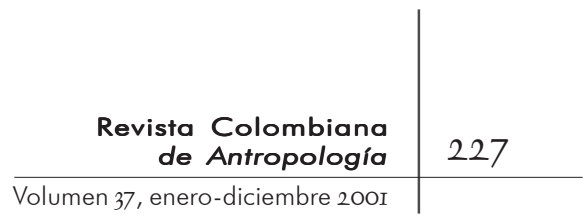

LinkENBACH, AnTJE. I992. "Ecological Movements and the critique of development: agents and interpreters". En Thesis Eleven. Number 39.

Little, Paul E. I999. "Environments and Environmentalism in Antropological Research: Facing a New Millennium”. En Annual Rev. Anthropology. $\mathrm{N}^{\mathrm{O}} 28$.

Milton, Kay. 1996. Environmentalism and Cultural Theory. Routledge. Londres y Nueva York.

Moore, Donald. I993. "Contesting Terrain in Zimbabwe's Eastern Highlands: Political Ecology, Ethnography, and Peasant Resources Struggles". Economic Geography. Vol. 69. No 4 .

1996. "Marxism, Culture, and Political Ecology. Environmental struggles in Zimbabwe's Eastern Highlands". En Richard Peet y Michael Watts (eds). Liberation Ecologies. Environment, development, social movements. Routledge. Londres.

1997. "Clear Waters and Muddied Histories: Environmental History and the Politics of Community in Zimbabwe's Eastern Highlands". Manuscrito.

Moran, Emilio. 1996. "Nurturing the Forest: Strategies of Native Amazonians”. En Roy Ellen y Katsuyoshi Fukui (eds.). Redefining Nature. Ecology, Culture and Domestication. BERG. Oxford.

_ 1993. La ecología humana de los pueblos de la amazonia. Fondo de Cultura Económica. México.

I992. "Deforestation and Land Use in the Brazilian Amazon". En Human Ecology. Vol. 2I. N ${ }^{\circ}$ I.

Nazarea, Virginia D. (ED.). I999. Ethnoecology, Situated Knowledge/ located lives. The University of Arizona Press. Tucson.

Nieto, Jairo A. 1989. El espacio ordenado: una manifestación de las relaciones culturales en el medio. Memorias V Congreso de antropología. ICFES.

Oelshlaeger, M. I99I. The idea of Wilderness: From Prehistory to the Age of Ecology. Yale University Press. New Haven y Londres.

Omvedt, Gail. 1993. Reinventing Revolution: New social Movements and the social tradition in India. M.E. Sharpe. Armonk.

Orlove, Benjamin S. 1980. "Ecological Anthropology". En Ann. Rev. Anthropology. $\mathrm{N}^{\mathrm{o}} 9$.

Osborn, Ann. 1995. Las cuatro estaciones. Banco de la República. Bogotá.

Painter, Michael. 1995. "Upland-Lowland Production Linkages and Land Degradation in Bolivia”. En Michael Painter y William H. 
Durham (eds.). The Social Causes of Environmental Destruction in Latin America. The University of Michigan Press.

Painter, Michael y William H. Durham. 1995. The Social Causes of Environmental Destruction in Latin America. The University of Michigan Press.

PÁLSson, Gisli. I996. "Human-Environmental Relations: Orientalism, Paternalism and Communism”. En Philippe Descola y Gisli Pálsson (eds.). Nature and Society. Anthropological Perspectives. Routledge. Londres.

Peet, Richard y Michael Watts. 1996. Liberation Ecologies. Routledge. Londres y Nuevaw York.

Pelusso, Nancy. 1992. Rich Forests, Poor People: Resource Control and Resistance in Java. University of California Press, Berkeley.

- I995. Whose Wood are these? Counter-mapping forest territories in Kalimantan, Indonesia, Antipode 27.

Pineda, Roberto. I999. "Sembrando la selva. Las raíces culturales de la biodiversidad”. En Revista Maguaré. No I4.

- 1990. "Convivir con las dantas". En La selva humanizada. Ecología alternativa en el trópico húmedo colombiano. François Correa (ed.): I09-I26, Instituto Colombiano de Antropología, Bogotá.

Posey, Darrell, John Frenchione, John Eddins, Luiz Francelino da Silva, Debbie Myers, Diane Case y Peter Macbeath. 1982. "Keepers of Forest". Garden 6.

Posey, DARRell. 1990. "Introduction to Ethnobiology". En Ethnobiology: Implications and applications. Museo Goeldi. Belem.

1984. "Ethnoecology as applied anthropology in Amazonian development". Human Organization. Vol. 43, No 2.

Princen, Thomas. 1994. "NGOs: Creating a Niche in Environmental Diplomacy". En Thomas Princen y Matthias Finger. Environmental NGOs in World Politics. Linking the local and the Global. Routledge. Londres y Nueva York.

RAPPAPORT, Roy. 1967. Pig for the Ancestors: Ritual an Ecology of a New Guinea People. Yale University Press. New Haven.

I97I. The Flow of Energy in an Agricultural Society. Scientific American. Vol. 225. No.3.

Reichel, Elizabeth. I995. "Diversidad amerindia, saberes y ciencia indígena: visión antropológica”. En Ciro Angarita et. al. Derecho, etnias y ecología. Colección Documentos de la Misión. Misión, ciencia, educación y desarrollo. Tomo 6. Colciencias. Bogotá. 


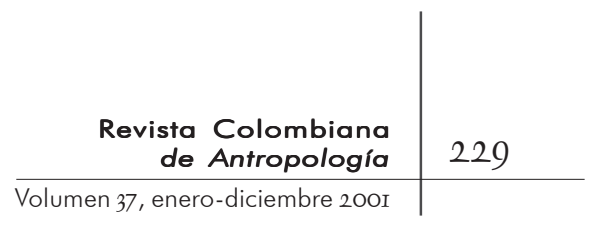

1989. "La danta y el delfín: manejo ambiental e intercambio entre dueños de malocas y chamanes. El caso yukuna-matapi (Amazonas)". Revista de Antropología i-2.

Reichel-Dolmatoff, Gerardo. 1967. "A brief Report on Urgent Ethnological Research in the Vaupés Area, Colombia, South América”. En Bulletin of the International Committe on Urgent Anthropological and Ethnological Research, $\mathrm{N}^{\circ}$ 9. Viena.

1968. Desana simbolismo de los indios Tukano del Vaupés. Universidad de los Andes. Departamento de Antropología. Bogotá.

- 1976. "Cosmology as ecological analysis. A view from the forest". Man II.

I978. "Desana animal categories, food restrictions, and the concept of color energies". En Journal of Latin American Lores. Vol. 4, No.2. Universidad de California. Los Angeles.

1988. Goldwork and Shamanism: An Iconographic Study of the Golden Museum. Editorial Colina. Colombia. Medellín.

1996. The Forest Within. The World-View of the Tukano Amazonian Indians. Themis Books. Londres.

Restrepo, Eduardo. I996. "Cultura y biodiversidad". En Arturo Escobar y Álvaro Pedrosa (editores). 1996. Pacífico: ¿desarrollo o diversidad? Cerec. Bogotá.

Rogel, Rosario y Eduardo Aguado. 2000. "Los desplazamientos en el discurso 'ecológico': del naturalismo social al sociologismo natural”. En Revista Convergencia. Año 7, número 22. Mayoagosto 2000. UAEM. México.

Rozo, Esteban. I999. "Naturaleza, paisaje y sensibilidad en la comisión corográfica". En Revista de Antropología y Arqueología. Vol. II. N ${ }^{0}$ I-2. 1999. Universidad de los Andes. Facultad de ciencias sociales. Departamento de antropología. Bogotá.

Rubio, Heidi, Astrid Ulloa, Mónica Rubio e indígenas embera. ig98. Tras las huellas de los animales. Icanh-Fundación NaturaMinisterio del Medio Ambiente-OEI-Orewa. Bogotá.

Rubio, Heidi, Astrid Ulloa y Claudia Campos. 2000. Manejo de fauna de caza, una construcción a partir de lo local. Orewa-OEIFundación Natura-Ministerio del Medio Ambiente-WWF-Icanh.

Sachs, Wolfgang (ED.). 1992. The Development Dictionary. Zed Books. Londres.

Sánchez, Enrique, María del Pilar Pardo, Margarita Floréz y Paola Ferreira. 2000. Protección del conocimiento tradicional. Instituto von Humboldt. Bogotá. 
Santos, Boaventura de Sousa. i998. La globalización del derecho. Los nuevos caminos de la regulación y la emancipación. IlsaUniversidad Nacional de Colombia. Bogotá.

SAntoyo, Álvaro. I999. "Paisajes presentes y futuros de la amazonia colombiana”. En Revista de Antropología y Arqueología. Vol. II. $\mathrm{N}^{\mathrm{o}}$ I-2. I999. Universidad de los Andes. Facultad de ciencias sociales. Departamento de antropología. Bogotá.

Serge, Margarita. I999. La concepción naturalista de la naturaleza. En Revista de Antropología y Arqueología. Vol. II. No I-2. I999. Universidad de los Andes. Facultad de ciencias sociales. Departamento de antropología. Bogotá.

Sethi, Harsh. 1993. "Survival and Democracy: Ecological Struggles in India”. En Ponna Wignaraja (ed.). New Social Movements in the South. Zed Books. Londres y Nueva Jersey.

Schultes, Richard y Robert RAFFAuf. I99O. The healing forest: medicinal and toxic plants of the northwest amazon. Dioscorides Press. Nueva York.

Steward, Julian. 1956. "Introduction". En The People of Puerto Rico, by. J.H. Steward. R.A. Manner, E. R. Wolf, E. Padilla Seda, S. W. Mintz, y R. L. Scheele. Urbana: University of Illinois Press.

— I977. "The Concept and Method of Cultural Ecology". En Julian Steward. Evolution and Ecology. University of Illinois Press. I946-I950. Handbook of South American Indians. Vols. I-6. Washington. D.C. Smithson. Inst.

Steward, Julian y L. Faron. 1959. Native Peoples of South America. McGraw-Hill. Nueva York.

Stone, Rosanne Allucquere. 1996. Desire and Technology at the Close of Mechanical Age. MIT Press. Cambridge.

Stonish, Susan. 1995. "Development, Rural Impoverishment, and Environmental Destruction in Honduras". En Michael Painter y William H. Durham (eds.). The Social Causes of Environmental Destruction in Latin America. The University of Michigan Press.

Strathern, Marilyn. ig92. Reproducing the Future: Anthropology, Kinship and the New Reproductive Technologies. Manchester University Press. Manchester.

Toledo, Victor. I989. Naturaleza, producción, cultura: ensayos de ecología política. Universidad Veracruzana. México.

Turbay, Sandra, Gustavo Gómez, Alba Doris López, Claudia Anzate y Olma Juny Álvarez. 1999. "Bestiario Momposino. Representaciones sobre animales en la isla de Mompox y el complejo cenagoso de 


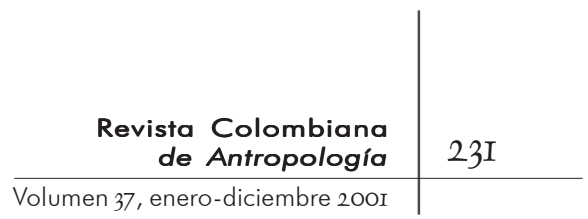

Pijiño”. Universidad de Antioquia-Colciencias-BID (informe sin publicar).

TURBAY, SANDRA. I997. Impacto de la explotación maderera sobre un grupo embera. Utopía Siglo XXI.

__ I994. "Los animales en la tradición zenú". En varios autores. Costa atlántica colombiana, etnología e historia. Memorias del VII Congreso de antropología en Colombia. Coimpresos, Medellín.

Ulloa, Astrid, Heidi Rubio y Claudia, Campos. ig96. Trua Wuandra. Estrategias para el manejo de fauna con comunidades embera en el parque nacional natural Utría. Chocó. Orewa-Fundación Natura-MMA-OEI. Bogotá..

UlLOA, Astrid. 200I. "El nativo ecológico: movimientos sociales y medio ambiente en Colombia”. En Movimientos sociales, Estado y democracia en Colombia. Mauricio Archila y Mauricio Pardo (editores). Icanh-CES-Universidad Nacional de Colombia. Bogotá.

I996. "Manejo tradicional de la fauna en procesos de cambio. Los embera en el parque nacional natural Utría”. En Investigación y manejo de fauna para la construcción de sistemas sostenibles. Cipav. Cali.

VAYDA, ANDrew. 1976. War in Ecological Perspective. Plenum. Nueva York. 1983. "Progressive Contextualization: methods for Research in human ecology". Human Ecology II.

Van der Hammen, María Clara. ig92. El manejo del mundo. Naturaleza y sociedad entre los yukuna de la amazonia colombiana. Tropenbos. Bogotá.

VAsco, Luis Guillermo. I99o. "Los embera-chamí en guerra contra los cangrejos”. En La selva humanizada. Ecología alternativa en el trópico húmedo colombiano. François Correa (ed.): Io9-I26, Instituto Colombiano de Antropología, Bogotá.

Viveiros de Castro, Eduardo. I996. "Images of Nature and Society in Amazonian Ethnology". En Annu. Rev. Anthropology. 25: 179-200.

1998. Cosmological deixis and Amerindian perspectivism. Journal of the Royal Anthropological Institute. 4: 469-88.

Von Hildebrand, Martin. i983. "Cosmovisión y el concepto de enfermedad entre los ufaina”. En Medicina, shamanismo y botánica: 48-63. Myriam Jimeno y Adolfo Triana (eds.). Funcol. Bogotá.

Wapner, Paul. 1994. "Environmental Activism and Global Civil Society”. En Dissent. Summer 4I.

I995. "Politics beyond the state: Environmental Activism and World Civic Politics". World Politics. Vol. 47. N ${ }^{\circ} 3$. 
Watts. Michael. 1983. Silent Violence: Food, Famine and Peasantry in North Nigeria, University of California Press. Berkeley.

White, LesLie. 1949. The Science of Culture: A study of Man and Civilization. Grove Press. Nueva York.

Wolf, ERIC. 1972. "Ownership and Political Ecology”. Anthropological Quartely 45 (3).

YaPa, LaKSHMAn. I996. "Improved Seeds and Constructed Scarcity". En Richard Peet y Michael Watts (eds.). Liberation Ecologies. Environment, development, social movements. Routledge. Londres.

Zimmerer, KarL S. I996. "Discourses on Soil Loss in Bolivia". En Richard Peet y Michael Watts (eds.). Liberation Ecologies. Environment, development, social movements. Routledge. Londres. 